NBER WORKING PAPER SERIES

\title{
THE SUPPLY SIDE OF INNOVATION: H-1B VISA REFORMS AND US ETHNIC INVENTION
}

\author{
William R. Kerr \\ William F. Lincoln \\ Working Paper 15768 \\ http://www.nber.org/papers/w15768
NATIONAL BUREAU OF ECONOMIC RESEARCH
1050 Massachusetts Avenue
Cambridge, MA 02138
February 2010

Comments are appreciated and can be sent to wkerr@hbs.edu and wlincoln@umich.edu. We thank Sarah Rahman for excellent research assistance. We thank seminar participants at AEA, ERSA, Federal Reserve Bank of Chicago, Harvard, ISIM, Michigan, MIT Sloan, NBER Innovation Policy and the Economy, NBER Labor Studies, NBER Productivity, and SOLE for helpful suggestions; we especially thank Lindsay Lowell and Debbie Strumsky for data assistance and Dan Aaronson, Ajay Agrawal, David Autor, Gadi Barlevy, Lisa Barrow, Charlie Brown, Jeff Campbell, Brendan Epstein, Richard Freeman, Jeff Furman, Luojia Hu, Jennifer Hunt, Larry Katz, Sari Kerr, Miles Kimball, Jacob Kirkegaard, Josh Lerner, Jim Levinsohn, Norm Matloff, Guy Michaels, Matt Mitchell, Ramana Nanda, Derek Neal, Paul Oyer, Jeff Smith, Dan Sullivan, and anonymous referees for their insights. This paper is a revised and shortened version of HBS Working Paper 09-005, and a subsequent version will be published in the Journal of Labor Economics. This research is supported by the Innovation Policy and the Economy group, Kauffman Foundation, Harvard Business School, the University of Michigan, the National Science Foundation, and the MIT George Shultz Fund. The views expressed herein are those of the authors and do not necessarily reflect the views of the National Bureau of Economic Research.

NBER working papers are circulated for discussion and comment purposes. They have not been peerreviewed or been subject to the review by the NBER Board of Directors that accompanies official NBER publications.

(C) 2010 by William R. Kerr and William F. Lincoln. All rights reserved. Short sections of text, not to exceed two paragraphs, may be quoted without explicit permission provided that full credit, including (C) notice, is given to the source. 
The Supply Side of Innovation: H-1B Visa Reforms and US Ethnic Invention

William R. Kerr and William F. Lincoln

NBER Working Paper No. 15768

February 2010

JEL No. F15,F22,J44,J61,O31

\begin{abstract}
$\underline{\text { ABSTRACT }}$
This study evaluates the impact of high-skilled immigrants on US technology formation. We use reduced-form specifications that exploit large changes in the $\mathrm{H}-1 \mathrm{~B}$ visa program. Higher $\mathrm{H}-1 \mathrm{~B}$ admissions increase immigrant science and engineering (SE) employment and patenting by inventors with Indian and Chinese names in cities and firms dependent upon the program relative to their peers. Most specifications find limited effects for native SE employment or patenting. We are able to rule out displacement effects, and small crowding-in effects may exist. Total SE employment and invention increases with higher admissions primarily through direct contributions of immigrants.
\end{abstract}

\author{
William R. Kerr \\ Harvard Business School \\ Rock Center 212 \\ Soldiers Field \\ Boston, MA 02163 \\ and NBER \\ wkerr@hbs.edu \\ William F. Lincoln \\ 8 QYHHUWIRIO IFKJDQ \\ Economics Department \\ 107 Lorch Hall \\ 611 Tappan St. \\ Ann Arbor, MI 48109-1220 \\ wlincoln@umich.edu
}




\section{Introduction}

The H-1B visa program governs most admissions of temporary immigrants into the US for employment in science and engineering (SE). This program has become a point of significant controversy in the public debate over immigration, with proponents and detractors at odds over how important $\mathrm{H}-1 \mathrm{~B}$ admission levels are for US technology advancement and whether native US workers are being displaced by immigrants. This study quantifies the impact of changes in $\mathrm{H}-1 \mathrm{~B}$ admission levels on the pace and character of US invention over the 1995-2008 period. We hope that this assessment aids policy makers in their current decisions about appropriate admission rates in the future.

The link between immigration policy and innovation may appear tenuous at first, but immigrant scientists and engineers are central to US technology formation and commercialization. Immigrants represented $24 \%$ and $47 \%$ of the US SE workforce with bachelor's and doctorate educations in the 2000 Census, respectively. This contribution was significantly higher than the $12 \%$ share of immigrants in the US working population. The growth of this importance in recent years is even more striking. From the Current Population Survey (CPS), we estimate that immigrant scientists and engineers accounted for more than half of the net increase in the US SE labor force since 1995.

Greater inflows and employment shares of educated immigrants do not necessarily increase

the pace of US innovation, however. Aggregate innovation could be unaffected, for example, if immigrants displace natives. To disentangle these issues, it is possible to exploit variation across dimensions like geography and industry. Establishing this variation is quite challenging with standard data sources, however, and partial correlations may not identify causal relationships in this context due to the endogeneity of immigrant location decisions.

To bring identification to this question, we exploit large changes in the H-1B worker population over the 1995-2008 period. The national cap on new H-1B admissions fluctuated substantially over these years, ranging from a low of 65,000 new workers a year to a high of 195,000. $\mathrm{SE}$ and computer-related occupations account for approximately $60 \%$ of $\mathrm{H}-1 \mathrm{~B}$ admissions, and changes in the H-1B population account for a significant share of the growth in US immigrant SE employment. In a reduced-form framework closely related to Card (2001), our empirical approach considers differences across US firms, cities, and states due to fluctuations in the H-1B population.

We first analyze CPS employment records for 1995-2008 using state-level variation. Growth in the H-1B program was associated with increased employment growth for immigrant scientists and engineers, especially among non-citizen immigrants. A $10 \%$ growth in the national H-1B 
population corresponded with a 2\%-4\% higher growth in immigrant SE employment for each standard deviation increase in state dependency. We do not find any substantive effect on native scientists and engineers across a range of labor market outcomes like employment levels, mean wages, and unemployment rates. We are able to rule out crowding-out effects, and our results suggest potentially small crowding-in effects. The total SE workforce in the state increased mainly through the direct contributions of immigrants. A $10 \%$ growth in the national $\mathrm{H}-1 \mathrm{~B}$ population corresponded with about a $0.5 \%$ higher growth in total SE employment for each standard deviation increase in state dependency.

While the CPS data afford direct observation of employment, wages, and immigration status, the data also have substantive limitations. To make additional progress and to more closely study the link between the H-1B program and US innovation, we devote the rest of the paper to characterizing differences in patenting behavior across cities and firms. We assemble micro-data on all US patent grants and applications through May of 2009. These base patent records offer complete patenting histories annually for cities and firms. Moreover, while immigration status is not directly observed, we can identify the probable ethnicities of inventors through their names. For example, inventors with the last names Gupta or Desai are more likely to be Indian than they are to be Anglo-Saxon or Vietnamese. This micro-level detail also allows us to analyze situations where no other data exist (e.g., how the H-1B program impacts the annual patenting contributions of Indian ethnicity inventors within Intel versus Proctor \& Gamble).

We find that increases in $\mathrm{H}-1 \mathrm{~B}$ admissions substantially increased rates of Indian and Chinese invention in dependent cities relative to their peers. A $10 \%$ growth in the $\mathrm{H}-1 \mathrm{~B}$ population corresponded with a 1\%-4\% higher growth in Indian and Chinese invention for each standard deviation increase in city dependency. We again find very little impact for native inventors as proxied by inventors with Anglo-Saxon names (who account for approximately $70 \%$ of all domestic patents). The evidence does not support crowding-out theories, and there is suggestive support for small crowding-in effects. Overall, a $10 \%$ growth in the H-1B population corresponded with a $0.3 \%-0.7 \%$ increase in total invention for each standard deviation growth in city dependency.

These city-level findings are robust to including a variety of regression controls like expected technology trends, labor market conditions, and region-year fixed effects. We also examine effects throughout the city dependency distribution and drop very dependent cities, firms, and sectors (e.g., computer-related patents). These tests help to confirm that our results are not due to endogenous changes in national $\mathrm{H}-1 \mathrm{~B}$ admissions following lobbying from very dependent groups. Finally, we show that our results for US cities are not reflected in a placebo experiment involving shifts in ethnic invention among Canadian cities. Section 4 also discusses some limitations of our analysis, especially around the lag structure of treatment effects. 
Our firm-level analysis creates a panel of 77 publicly listed firms that account for about a quarter of US patents. Within this group, we again find that invention rates of more $\mathrm{H}-1 \mathrm{~B}$ dependent firms are particularly sensitive to the size of the program. A $10 \%$ growth in the H-1B population corresponded with a 4\%-5\% higher growth in Indian and Chinese invention for each standard deviation increase in firm dependency. These elasticities are particularly strong for computer-oriented firms (e.g., Microsoft, Oracle) relative to firms in other sectors.

Our project most directly relates to recent empirical studies on the relationship between immigration and US innovation. Peri (2007) and Hunt and Gauthier-Loiselle (2008) explore long-run relationships between immigration and patenting rates using state-decade variation. The latter study in particular finds substantial crowding-in effects for native scientists and engineers. Chellaraj et al. (2008) also find strong crowding-in effects when using time-series variation. In contrast, Borjas $(2005,2006)$ finds that natives are crowded-out from graduate school enrollments by foreign students, especially in the most elite institutions, and suffer lower wages after graduation due to increased labor supply. This disagreement in the academic literature is reflected in the public debate over high-skilled immigration and the H-1B visa in particular.

Our paper contributes to this research through its measurement of ethnic patenting and the use of $\mathrm{H}-1 \mathrm{~B}$ policy changes for the identification of immigrant SE inflows. Our limited effects for natives fall in between the results of prior academic work and the effects suggested in the public debate. This may reflect the high-frequency variation that we exploit and institutional features of the H-1B program that we discuss below. We also contribute to the literature through the first description of ethnic invention within firms and the first characterization of the firm-level link between immigration and innovation. Understanding these mechanisms is important as immigration policies influence firms, universities, and other institutions differently. ${ }^{1}$

In a broader context, we view this paper as a building block for describing the supply side of innovation. The demand side of the economy governs the pace of innovation in most models of endogenous growth; larger markets encourage greater entrepreneurial innovation due to profit incentives. In these basic frameworks, labor adjusts freely across research and production sectors, and high-skilled labor inflows do not increase innovation except trivially through larger economy size. There are, however, at least two deeper channels through which immigration can influence innovation. First, there are often significant adjustment costs when workers move across occupations and sectors, particularly when moving into research-oriented occupations.

\footnotetext{
${ }^{1}$ Related papers describing the contributions of immigrants to US science and engineering include Stephan and Levin (2001), Saxenian (2002), Matloff (2003, 2004), Miano (2005, 2008), NFAP (2008), Lowell and Christian (2000), Wadhwa et al. (2007), Kerr (2008), and Hunt (2009). Freeman (2006) surveys global labor flows and discusses their deep scientific impacts. General surveys of immigration include Borjas (1994), Friedberg and Hunt (1995), and Kerr and Kerr (2008). Foley and Kerr (2008) examine the firm-level link between immigration and FDI.
} 
These slower adjustments open up the possibility for supply shocks to US innovation through shifts in immigration policy. Second, the sharing of ideas across countries can lead directly to higher levels of innovation. We believe that these effects can be large with high-skilled immigration, especially when the knowledge needed to create new ideas is tacit. We hope that future research studies these mechanisms in greater detail. ${ }^{2}$

\section{US Ethnic Invention}

We quantify ethnic technology development in the US through the individual records of all patents granted by the United States Patent and Trademark Office (USPTO) from January 1975 to May 2009. Each patent record provides information about the invention (e.g., technology classification, firm or institution) and the inventors submitting the application (e.g., name, city). Hall et al. (2001) provide extensive details about these data, and Griliches (1990) surveys the use of patents as economic indicators of technology advancement. The data are extensive, with over eight million inventors and four million granted patents during this period.

While immigration status is not collected, one can determine the probable ethnicities of inventors through their names. USPTO patents must list at least one inventor, and multiple inventors are often listed. Our approach exploits the idea that inventors with the surnames Chang or Wang are likely of Chinese ethnicity, those with surnames Rodriguez or Martinez of Hispanic ethnicity, etc. Two commercial ethnic name databases originally used for marketing purposes are utilized, and the name-matching algorithms have been extensively customized for the USPTO data. The match rate is 99\%. Kerr (2007) provides further details on the matching process, lists frequent ethnic names, and provides multiple descriptive statistics and quality assurance exercises. As our regressions employ ethnic patenting for dependent variables, remaining measurement error in inventor ethnicities will not substantively influence the consistency of our estimates. ${ }^{3}$

Figure 1 illustrates the evolving ethnic contribution to US technology development as a percentage of patents granted by the USPTO. These descriptive statistics and the regression analyses below only use patents filed by inventors residing in the US (with the exception of the Canadian regressions). When multiple inventors exist on a patent, we make individual ethnicity assignments for each inventor and then discount multiple inventors such that each patent receives the same weight. We group patents by the years in which they applied to the USPTO. For

\footnotetext{
${ }^{2}$ For related research on these issues, see Acemoglu and Linn (2004), Barro and Sala-i-Martin (1995), Freeman (1971), Siow (1984), Rivera-Batiz and Romer (1991), Ryoo and Rosen (2004), and Furman et al. (2002).

${ }^{3}$ One of our quality assurance exercises regards the estimated ethnic composition of foreign patents registered with the USPTO. The resulting compositions are quite reasonable. About 90\% of inventors filing from India and China are classified as ethnically Indian and Chinese, respectively. This is in line with what we would expect, as native shares should be less than $100 \%$ due to the role that foreign inventors play in these countries.
} 
presentation purposes, Figure 1 does not include the Anglo-Saxon and European ethnic shares. They jointly decline from $90 \%$ of total US domestic patents in 1975 to $76 \%$ in 2004 . This declining share is primarily due to the exceptional growth over the 30 years of the Chinese and Indian ethnicities, which increase from under $2 \%$ to $9 \%$ and $6 \%$, respectively.

We define cities through 281 Metropolitan Statistical Areas. In descriptive analyses, we find that ethnic inventors are generally concentrated in gateway cities closer to their home countries (e.g., Chinese in San Francisco, Hispanics in Miami). Not surprisingly, total patenting shares are highly correlated with city size, and the three largest shares of US domestic patenting for 1995-2004 are San Francisco (12\%), New York City (7\%), and Los Angeles (6\%). Ethnic patenting is generally more concentrated, with shares for San Francisco, New York City, and Los Angeles being 22\%, 10\%, and 9\%, respectively. Indian and Chinese invention are even further agglomerated. San Francisco shows exceptional growth from an $8 \%$ share of total US Indian and Chinese patenting in 1975-1984 to $26 \%$ in 1995-2004, while New York City's share declines from $17 \%$ to $10 \%{ }^{4}$

Figures 2 and 3 provide a more detailed view of Indian and Chinese contributions for different technology sectors. These two ethnicities are more concentrated in high-tech sectors than in traditional fields, and their growth as a share of US innovation in the 1990s is remarkable. A large portion of this growth is due to the rapid economic development of these countries and their greater SE integration with the US. Similarly, sustained US economic growth made America attractive as a host country. The US Immigration Act of 1990 also facilitated greater permanent immigration of SE workers from large countries like India and China (e.g., Kerr 2008).

Figure 2 exhibits an interesting downturn in the Indian share of computer-related invention after 2000, which includes software patents. This shift from strong growth in the 1990s is striking and may reflect more restrictive US immigration policies. Many factors likely contributed to this shift, however, such as the high-tech recession and the increasing attractiveness of foreign opportunities like Bangalore. Accordingly, our estimations control for these aggregate trends.

As a final descriptive feature, it is important to assess whether major differences exist across ethnicities in the quality of innovations. The most tractable approach for our sample is to examine the number of claims made by patents filed by different ethnicities. Each patent includes a series of claims that delineate the property rights of the technology. These claims define the novel features of each invention from prior inventions and become a crucial factor in future patent infringement litigations. USPTO examiners review and modify the claims argued for by inventors in their applications, and several studies link the granted number of claims on a patent with its economic value. The average claims on Indian (19.7) and Chinese (18.9) patents

\footnotetext{
${ }^{4}$ Agrawal et al. (2008) and Kerr (2009) further describe ethnic inventor agglomeration.
} 
are slightly above the sample average of 18.8. This comparability holds in simple regressions that control for technology category by year fixed effects. ${ }^{5}$

While the ethnic patenting data provide a tractable platform for examining immigration and innovation, several limitations exist. First, our approach does not distinguish between foreignborn inventors working in the US and later generations. Our panel econometrics, however, identify off of relative changes in ethnic inventor populations. For Indian and Chinese inventors, these changes are mainly due to new immigration or school-to-work transitions that require a visa, weakening this overall concern. Similarly, we study native outcomes through inventors with Anglo-Saxon names. In addition to capturing effects on US natives, inventors with Anglo-Saxon names also reflect some immigration from the UK, Canada, etc. Relative magnitudes suggest that this second factor is very small, however. Canada and the UK account for about 10,000 new H-1B workers annually over the $2000-2005$ period, a small number compared to a native SE workforce of more than 2.5 million. Our CPS analysis further addresses these concerns. ${ }^{6}$

\section{H-1B Visa Program}

The H-1B visa is a temporary immigration category that allows US employers to seek shortterm help from skilled foreigners in "specialty occupations." These occupations are defined as those requiring theoretical and practical application of specialized knowledge like engineering or accounting; virtually all successful H-1B applicants have a bachelor's education or higher. The visa is used especially for SE and computer-related occupations, which account for roughly $60 \%$ of successful applications. Approximately $40 \%$ and 10\% of H-1B recipients over 2000-2005 came from India and China, respectively. Shares for other countries are less than $5 \%{ }^{7}$

The sponsoring firm files the $\mathrm{H}-1 \mathrm{~B}$ application and must specify an individual candidate.

\footnotetext{
${ }^{5}$ Hunt (2009) finds that immigrants entering on temporary work visas or student/trainee visas typically outperform natives in patenting and related activities. This greater performance is mostly explained by immigrants' higher education and selected fields of study. Thus, the disproportionate contributions of immigrant scientists and engineers come primarily through greater involvement and training for SE fields.

${ }^{6}$ The base data contain information on all patents granted from January 1975 to May $2009 . \quad$ Application years of patents, however, provide the best description of when innovative research is being undertaken due to substantial and uneven lags in USPTO reviews. Inventors also have strong incentives to file for patent protection as soon as their research project is sufficiently advanced. Accordingly, our annual descriptions are measured through patent application years. This standard approach leads to sample attrition after 2004 as many applications have not yet been processed for approval when our data were collected. To compensate for this, we also employ a data set of over one million published patent applications, which the USPTO began releasing in 2000. Our preferred data set combines the patent grants and applications data, removing applications that have been granted. This union yields more consistent sample sizes in later years. We also consider estimations that only use grants data in robustness checks and come to similar conclusions.

${ }^{7}$ Broad statistics on the H-1B program are taken from reports submitted annually to Congress: "Characteristics of Specialty Occupation Workers (H-1B)." Data on source countries compositions are only publicly available for the period 2000-2005. Lowell and Christian (2000), Lowell (2000), Matloff (2003), and Kirkegaard (2005) provide additional details on the H-1B program. Facchini et al. (2008) and Hunt (2009) overview other temporary immigration categories.
} 
The employer-employee match must therefore be made in advance. ${ }^{8}$ Workers are tied to their sponsoring firm, although some recent changes have increased visa portability. Firms can petition for permanent residency (i.e., a green card) on behalf of the worker. If permanent residency is not obtained, the $\mathrm{H}-1 \mathrm{~B}$ worker must leave the US at the end of the visa period for one year before applying again. Firms are also required to pay the visa holder the higher of (1) the prevailing wage in the firm for the position or (2) the prevailing wage for the occupation in the area of employment. These restrictions were designed to prevent H-1B employers from abusing their relationships with foreign workers and to protect domestic workers. ${ }^{9}$

Since the Immigration Act of 1990, there has been an annual cap on the number of H-1B visas that can be issued. The cap governs new $\mathrm{H}-1 \mathrm{~B}$ visa issuances only; renewals for the second three-year term are exempt, and the maximum length of stay on an $\mathrm{H}-1 \mathrm{~B}$ visa is thus six years. While most aspects of the $\mathrm{H}-1 \mathrm{~B}$ program have remained constant since its inception, the cap has fluctuated significantly. The largest amount of controversy about the H-1B program focuses on this cap. Indeed, a search of Lexis-Nexis finds more than three thousand news articles about the visa from 1995-2006. Executives of high-tech firms often argue that higher H-1B admissions are necessary to keep US businesses competitive, to spur innovation and growth, and to keep firms from shifting their operations abroad. Detractors, on the other hand, argue that the program displaces American workers, lowers wages, and discourages on-the-job training.

Figure 4 uses fiscal year data from the United States Citizenship and Immigration Services (USCIS) to plot the evolution of the numerical cap. ${ }^{10}$ The 65,000 cap was not binding in the early 1990s but became so by the middle of the decade. Legislation in 1998 and 2000 sharply increased the cap over the next five years to 195,000 visas. The language contained in the 1998 legislation argued that "American companies today are engaged in fierce competition in global markets" and "are faced with severe high-skill labor shortages that threaten their competitiveness." These short-term increases were allowed to expire during the US' high-tech downturn, when visa demand fell short of the cap. The cap returned to the 65,000 level in 2004 and became binding again, despite being subsequently raised by 20,000 through an "advanced degree" exemption. $^{11}$

\footnotetext{
${ }^{8}$ Different employers can simultaneously seek visas for the same prospective employee, although firms generally make applications only on behalf of committed workers due to the time and legal fees involved. The application fee for a firm with 26 or more full-time employees was $\$ 2,320$ in 2008 .

${ }^{9}$ Studies of the impact of H-1Bs on wages are mixed and include Lowell (2001), Zavodny (2003), Matloff (2003, 2004), Kirkegaard (2005), Miano (2005), Tambe and Hitt (2009), Mithas and Lucas (2009), and Hunt (2009).

${ }^{10}$ The USCIS is the successor to the Immigration and Naturalization Service (INS).

${ }^{11}$ The two legislations are the American Competitiveness and Workforce Improvement Act of 1998 and the American Competitiveness in the Twenty-First Century Act of 2000. See Reksulak et al. (2006) and Public Law 105-777, Division C, American Competitiveness and Workforce Improvement Law, Section 416(c)(2).

Unlike permanent immigration, immediate family members of the $\mathrm{H}-1 \mathrm{~B}$ worker do not count towards the visa cap. These family members are, however, restricted from working unless they otherwise obtain an appropriate work visa. Free trade agreements require that 1,400 and 5,400 of the visas be reserved for citizens of Chile and Singapore, respectively. These special allotments are often under-utilized, however, and excess visas are returned to the general pool. In recent years, additional extensions have been granted for $\mathrm{H}-1 \mathrm{~B}$ holders who are still waiting for permanent residency approval when their initial six years have expired.
} 
These adjustments to the H-1B cap are large enough to be economically important. Backof-the-envelope calculations using the CPS suggest that raising the H-1B cap by 65,000 visas would increase the US SE labor force by about 1.2\%, holding everything else constant. This increase would be about half of the median annual growth rate of SE workers, calculated at $2.7 \%$ during the period. Thus, while the H-1B program does not have the size to dramatically alter aggregate levels of US invention in the short run, it does have the size to substantially influence the growth rate of US innovation, which is what our empirical specifications test. These effects on the growth of innovation can have very significant impacts on economic growth and aggregate welfare when compounded over time.

The two closest temporary worker visas to the H-1B are the L-1 and TN visas. Neither of these visa categories is a particularly good substitute for the H-1B. The L-1 is issued to multinationals in order to bring in managers or employees with "specialized knowledge" that have worked for the firm abroad for at least one year. The TN visa was established under NAFTA and allows citizens from Mexico and Canada to work in the US in certain high-skilled occupations. Both of these programs are less than $10 \%$ of the size of the $\mathrm{H}-1 \mathrm{~B}$ program for high-tech workers during the 1995-2006 period and contain institutional features that limit firms' ability to use them to circumvent the H-1B quota. Neither visa category shows substantial increases after the H-1B cap was dramatically reduced in 2004, and the Department of Homeland Security has argued that limited substitution exists across the H-1B and L-1 visas. ${ }^{12}$

Prior research on the $\mathrm{H}-1 \mathrm{~B}$ program is mostly descriptive due to data limitations. Indeed, data constraints significantly shape our empirical approach discussed below. The most important work for our study are estimates of the H-1B entry rates and population stocks, neither of which is definitively known. Lowell (2000) builds a demographic model for this purpose that factors in new admissions and depletions of the existing $\mathrm{H}-1 \mathrm{~B}$ pool by transitions to permanent residency, emigration, or death. While $\mathrm{H}-1 \mathrm{~B}$ inflows are reasonably well measured, the latter outflows require combining available statistics with modelling assumptions. In Lowell's model, emigration and adjustment to permanent residency are roughly comparable in magnitude, with the time spent from entry to either event being estimated through typical H-1B experiences.

Figure 4 shows Lowell's updated estimates provided to us for this paper. The H-1B population grew rapidly in the late 1990s before leveling off after 2000. The lack of growth immediately after 2000 can be traced to weak US employment opportunities for scientists and engineers during the high-tech recession. When demand returned, however, the reduced supply of H-1B visas restricted further growth. This constraint is obscured in Figure 4, where entry rates exceed the cap. This decoupling of the numerical cap and $\mathrm{H}-1 \mathrm{~B}$ entry rates is due to the American Competitiveness in the Twenty-First Century Act of 2000. This legislation made universities,

\footnotetext{
${ }^{12}$ Our earlier working paper further discusses the L-1 and TN visas. This paper is available at http://www.people.hbs.edu/wkerr/.
} 
government research labs, and certain nonprofits exempt from the cap and took effect in fiscal year 2001. We consequently focus on patents from the private sector that remain subject to the cap and that constitute the vast majority of patents. We also test whether using Lowell's population estimates or a measure based solely on the cap influences our results.

Firms in particular remain subject to the cap, and their growth in $\mathrm{H}-1 \mathrm{~B}$ usage has been constrained by recent lower admissions levels. USCIS begins accepting applications on April 1st for the following fiscal year and announces when the cap is reached. It has been reached in every fiscal year since the cap was lowered in 2004, often on the first day of accepting applications. A lottery has been used since 2006 among firms that applied close to the cut-off date. Whether or not a shortage of SE workers exists is strongly debated (e.g., Lowell and Salzman 2007). Unemployment rates for SE workers are typically quite low (e.g., Kannankutty 2008), but a number of studies document stagnating SE wages compared to similarly skilled occupations (e.g., Lemieux 2007).

Beyond these broad statistics, data regarding the H-1B program are very limited. Our primary data source in this regard is the published micro-records on Labor Condition Applications (LCAs). To obtain an H-1B visa, an employer must first file an LCA with the US Department of Labor (DOL). The primary purpose of the LCA is to demonstrate that the worker in question will be employed in accordance with US law. The second step in the application process after the LCA is approved is to file a petition with the USCIS, which makes the ultimate determination about the visa application. The DOL releases micro-records on all applications it receives, numbering 1.8 million for 2001-2006. These records include firm names and proposed work locations. ${ }^{13}$ We use these data to describe both city and firm dependencies, although it should be noted that LCA approvals do not translate one-for-one into H-1B grants.

\section{Spatial Analyses of the H-1B Program}

\subsection{Empirical Framework}

We seek to quantify the impact of changing H-1B admission levels on SE employment and innovation. We are unlikely to successfully capture this relationship using aggregate trends given the many contemporaneous changes to the US economy over the past two decades. We thus need to exploit variation across more narrowly defined labor markets within the US. Such variation allows us to control for national changes and thereby use relative differences in localized expansions or contractions to measure the H-1B program's effects.

\footnotetext{
${ }^{13}$ Our earlier working paper describes in greater detail the preparation of all data employed in this study.
} 
We take cities to be the primary labor market for this analysis, a decision further discussed below. Defining $\mathrm{H}-1 \mathrm{~B}_{c, t}$ as the stock of $\mathrm{H}-1 \mathrm{~B}$ immigrants in city $c$ in year $t$, the impact of the $\mathrm{H}-1 \mathrm{~B}$ program could in principle be estimated with a panel specification of the form

$$
S E_{c, t}=\phi_{c}+\eta_{t}+\tilde{\beta} \cdot \ln \left(\mathrm{H}-1 \mathrm{~B}_{c, t}\right)+\tilde{\epsilon}_{c, t}
$$

where $\phi_{c}$ and $\eta_{t}$ are city and year fixed effects. Year effects would control for aggregate time trends, and city effects would account for permanent differences across cities. The dependent variables of interest would include log employment of different types of SE workers, log SE wages, and log patents. The $\tilde{\beta}$ coefficient would measure how much growth in the local H-1B population impacted the corresponding outcome variable of interest.

There are several challenges, however, to specification (1). Most immediately, population estimates of $\mathrm{H}-1 \mathrm{~B}_{c, t}$ do not exist due to data constraints. Second, even if these data existed, the resulting model would likely return a biased estimate of the true $\tilde{\beta}$ parameter. Local H-1B populations are not randomly assigned, and their growth may be correlated with the error term $\tilde{\epsilon}_{c, t}$. The firm-sponsored nature of the visa and its intended use for labor scarcity, moreover, would make the direction of this endogeneity and resulting bias ambiguous. ${ }^{14}$

Due to these issues, we implement a variant of the supply-push immigration framework of Card (2001). We test whether shifts in national H-1B admissions are associated with stronger or weaker SE employment and innovation in cities that are very dependent upon the program relative to less dependent peers. Defining $\mathrm{H}_{-} 1 \mathrm{~B}_{c}$ as city $c$ 's fixed dependency on the program and $\mathrm{H}-1 \mathrm{~B}_{t}$ as the national $\mathrm{H}-1 \mathrm{~B}$ population, the modified estimating framework is

$$
S E_{c, t}=\phi_{c}+\eta_{t}+\beta \cdot\left[\mathrm{H}-1 \mathrm{~B}_{c} \cdot \ln \left(\mathrm{H}-1 \mathrm{~B}_{t}\right)\right]+\epsilon_{c, t},
$$

where main effects for $\mathrm{H}-1 \mathrm{~B}_{c}$ and $\ln \left(\mathrm{H}-1 \mathrm{~B}_{t}\right)$ are absorbed into the panel fixed effects. Thus, framework (2) only exploits the residual variation in the interaction for identification.

This equation is a reduced-form estimate of the true relationship (1). The $\beta$ coefficient measures the impact of national H-1B population growth on outcomes of interest in more dependent versus less dependent cities. This approach properly identifies treatment effects if (1) national $\mathrm{H}-1 \mathrm{~B}$ admission decisions are made exogenously by the federal government, (2) the national changes have heterogeneous impacts across cities due to differences in fixed dependencies, and (3) neither of the terms are correlated with omitted factors that also shape SE employment and patenting outcomes. Failure of these conditions would again lead to biased estimates. For example, national technology trends may be correlated with $\mathrm{H}-1 \mathrm{~B}$ policy adjustments, and

\footnotetext{
${ }^{14}$ For example, an upward bias for native employment outcomes may result from localized productivity or technology shocks simultaneously increasing H-1B and native SE labor demand. On the other hand, a downward bias may result from situations where firms employ $\mathrm{H}-1 \mathrm{~B}$ workers to overcome a declining ability to attract native SE workers to the city (e.g., due to weakening amenities).
} 
the former can independently produce employment differences across cities if technology compositions closely align with cities' H-1B dependencies. Alternatively, the interaction will not overcome the endogeneity problem if very dependent firms and cities influence the size of the program established by the federal government through lobbying or similar activities (e.g., Reksulak et al. 2006, Facchini et al. 2008). Our empirical analysis will thus test for these issues.

We now describe more closely the two elements of the interaction. The interaction term does not recover the true $\tilde{\beta}$ coefficient of interest, and we must carefully define the variables to provide scale and intuition for the results. First, $\mathrm{H}-1 \mathrm{~B}_{t}$ is Lowell's measure of the visa-holding population. We lag the years shown in Figure 4 by one year to align USCIS fiscal years with calendar years. Before interacting, logarithms of $\mathrm{H}-1 \mathrm{~B}_{t}$ are taken to remove scale dependency. Second, we develop two estimates of $\mathrm{H}-1 \mathrm{~B}_{c}$, which are described shortly. We normalize each of these dependency measures to have unit standard deviation before interacting.

Our first measure of a city's H-1B dependency is derived from the DOL microdata on LCAs. This measure is constructed as the yearly average of the city's LCAs in 2001-2002 normalized by the city population. There are several advantages of this metric. First, it is very closely tied to the H-1B program and can be measured for all cities. Second, the metric can be extended to the firm level, a disaggregation that we exploit in Section 5. Finally, LCAs measure latent demand for $\mathrm{H}-1 \mathrm{~B}$ visas; demand is measured independent of whether an $\mathrm{H}-1 \mathrm{~B}$ visa is ultimately realized or not. Moreover, measured demand is real in that non-trivial application and legal costs exist, and firms must list individual candidates on accompanying documents.

These strengths of the LCA-based dependency make it our preferred metric, but it does have important weaknesses. Our primary concern is that the dependency is measured at a mid-point during the sample period, rather than in a pre-period. To the extent that cities endogenously develop stronger attachment to the H-1B program, our measured dependency is not really fixed cross-sectionally and will lead to upwardly biased treatment effects. Second, the LCA data also have some noise in actual $\mathrm{H}-1 \mathrm{~B}$ visa placement. While the $\mathrm{H}-1 \mathrm{~B}$ visa is granted for a specific worker and a specific location, one of the most common abuses of the program is for firms to shift workers illegally to other locations. A 2008 USCIS investigation found violations of this nature in $11 \%$ of sampled $\mathrm{H}-1 \mathrm{~B}$ cases (compared to $6 \%$ of cases where the prevailing wage was not being paid). This measurement error will tend to bias treatment effects downward. ${ }^{15}$

Given these weaknesses of the LCA metric, our second measure of $\mathrm{H}-1 \mathrm{~B}_{c}$ is the 1990 count of non-citizen immigrant scientists and engineers in the city with bachelor's educations or above, again normalized by city population. This metric is calculated from the 1990 Census of Populations and is much more conservative, being entirely measured before the 1990s growth in SE

\footnotetext{
${ }^{15}$ Overall, the 2008 USCIS study found fraud or technical violations in $20 \%$ of sampled H-1B cases, with incident rates especially high among small employers and business services firms (e.g., accounting, human resources, sales).
} 
immigration evident in Figures 1-3. This measure also has the nice advantage of allowing contrasts with Canadian cities that we exploit below. It is very closely related to the measures used in Card (2001) and Hunt and Gauthier-Loiselle (2008), albeit with a focus on local SE employment. Its primary disadvantage is that the non-citizen immigrant category includes permanent residents and other temporary workers besides H-1B holders (e.g., exchange visitors, students). Measurement error in the regressor of this form will bias elasticity estimates downward from their true treatment effects.

Table 1 documents the most dependent cities and states. A number of big cities are dependent upon the $\mathrm{H}-1 \mathrm{~B}$ program, which is similar to other immigration clustering, but many smaller cities are influenced as well. San Francisco is the most dependent city in the LCA-based ranking. In the Census-based ranking, Lafayette-West Lafayette, IN, and Bryan-College Station, TX, are ranked higher than San Francisco. These cities are home to Purdue University and Texas A\&M University, respectively, and their surrounding SE industries. Other heavily dependent cities include Raleigh-Durham, Boston, and Washington, although considerable variation exists outside of the top rankings. The least dependent cities are Pascagoula, MS, and Rapid City, SD, according to the LCA and Census metrics, respectively. The bottom $40 \%$ of cities includes 16 cities with populations in 1994 greater than half a million. Prominent examples are San Antonio, TX, Tampa-St. Petersburg, FL, Providence, RI, and Norfolk-VA Beach, VA. The pairwise correlation of the two rankings is 0.5 across all cities.

We now return to the definition of cities as the relevant market for these effects. The appropriate market definition should reflect the speeds of SE labor, product, and technology flows. While the SE market is national in scope in the long-run, we believe that cities are an appropriate choice for a short-run analysis given the location-specific nature of $\mathrm{H}-1 \mathrm{~B}$ visas, local labor mobility, and short-run rigidities in firm location choices. ${ }^{16}$ We generally prefer cities to states as economic units in this context, although data limitations require us to study the latter when using the CPS. For example, a state-level dependency for North Carolina would mask substantial differences between Raleigh-Durham and Wilmington, among the most and least H-1B dependent cities nationally. From an econometric perspective, city-level granularity also allows for stronger regional trends and controls. We further exploit some sector-level variation in robustness checks and our firm-level analyses. ${ }^{17}$

These decisions may influence our measured treatment effects. For many variables, we would anticipate a positive $\beta$ coefficient regardless of the variation exploited. For example, one would

\footnotetext{
${ }^{16}$ Agglomeration studies typically identify cities and commuting regions as the relevant spatial unit for labor market effects on firms, and technology spillovers are found to operate at even shorter distances. For example, Rosenthal and Strange (2001), Ellison et al. (2009), and Glaeser and Kerr (2009).

${ }^{17}$ Borjas (2003) argues analyzing immigration through education-experience cells under the assumption of an otherwise national labor market. The H-1B program is almost entirely confined to workers with bachelor's education levels and above, limiting the effectiveness of this technique.
} 
anticipate that localized growth in $\mathrm{H}-1 \mathrm{~B}$ populations would increase employment of temporary immigrant scientists and engineers or patents by Indian and Chinese inventors whether looking across cities, industries, or occupations. Of course, the magnitudes of these effects are unknown and important to assess.

For effects on natives, however, even the sign of the $\beta$ coefficient is unclear as immigrants may substitute or complement native workers. A negative coefficient would suggest that natives are crowded-out of SE employment or patenting by H-1B workers, either through direct replacement within firms or through worker choices (e.g., switching occupations due to lower salaries). On the other hand, crowding-in effects could exist. For example, employing immigrants with special SE skills may lead firms to devote more resources to R\&D, thereby expanding employment and innovative activity for natives. Moreover, agglomeration economies may exist at the city level. If $\mathrm{H}-1 \mathrm{~B}$ expansions lead to greater $\mathrm{SE}$ employment and innovation in an area, similar firms may benefit from locating nearby or expanding employment in local facilities. These agglomeration forces are particularly strong in innovative fields and are one of the central ways that the economics of high-skilled immigration may differ from low-skilled immigration.

Finally, it is important to stress that our empirical analysis of the H-1B program emphasizes short-term effects. Several channels through which immigrant scientists and engineers may impact the US economy operate over longer horizons than the panel considered (e.g., adjusting college major choices for natives, immigrants starting entrepreneurial firms). These effects may lead to long-run effects that differ from our work.

\subsection{CPS State-Level Employment Outcomes}

Our first analysis considers employment outcomes in the CPS at the state level over the 19952008 period. This analysis is a nice starting point as employment and wage patterns most directly relate to the theoretical framework outlined above and are themselves a central policy concern. Since 1994, the CPS has identified whether respondents are non-citizen immigrants, citizen immigrants, or US natives. This reporting of immigration status is also an important complement to our patenting analysis where immigration status is inferred.

The CPS, however, also brings substantial liabilities. Most importantly, the CPS is designed as a representative sample for the US, not for small geographic areas like cities and states. As a consequence, immigrant SE records are incomplete for a quarter of potential state-year observations. Even for complete series, small sample sizes also result in substantial measurement error. Second, the CPS redesign in 2003 creates a structural break in variable definitions between 2002 and 2003. As a consequence, we employ a first-differenced version of specification (2) that 
drops 2002-2003 changes. This dropped year is an important inflection point for the H-1B program, but we unfortunately cannot separate economic changes from survey coding changes. ${ }^{18}$

Regressions are unweighted and cluster standard errors at the cross-sectional level by state; we discuss our clustering choices further in the city analysis below. In addition to year fixed effects, we also control for contemporaneous changes in state labor market conditions with several unreported controls. These controls help isolate the impact of the H-1B program from unmodeled factors specific to states and from CPS variable redefinitions. ${ }^{19}$

Table 2 presents the CPS results with Panels A and B utilizing LCA-based and Censusbased dependencies, respectively. Column 1 finds growth in non-citizen immigrant scientists and engineers with higher $\mathrm{H}-1 \mathrm{~B}$ admission rates. A $10 \%$ growth in the national $\mathrm{H}-1 \mathrm{~B}$ population corresponded with a 3\%-4\% higher growth in non-citizen immigrant SE employment for each standard deviation increase in state dependency. The $\beta$ estimates are statistically precise and economically meaningful in size. Moreover, the $10 \%$ increase discussed is realistic as the average annual increase in the $\mathrm{H}-1 \mathrm{~B}$ population during the sample period is $7 \%$.

Column 2 finds a weaker elasticity for employment growth of all immigrant SE workers, which is to be expected. Column 3 finds very limited effects on native SE workers. The point estimates suggest a growth of $0.1 \%-0.4 \%$ with a $10 \%$ increase in the $\mathrm{H}-1 \mathrm{~B}$ population, but these estimates are not statistically different from no effect at all. In aggregate, Column 4 suggests a $0.3 \%-0.6 \%$ growth in the total SE workforce following a $10 \%$ growth in the national $\mathrm{H}-1 \mathrm{~B}$ population per standard deviation increase in state dependency. The $0.6 \%$ outcome with the LCA-based measure is statistically significant, while the Census-based elasticity is not. ${ }^{20}$

The final three columns consider three other outcome measures for native SE workers with bachelor's educations and higher: labor force participation rates, unemployment rates, and mean weekly wages. We present a battery of measures as effects for natives may come through different forms (e.g., unemployment rates may be misleading in this context to the extent that natives are pushed into part-time work). The point estimate with LCA-based dependency suggests a $1 \%$ decline in native SE weekly wages, but this effect is not statistically significant. The remaining

\footnotetext{
${ }^{18}$ Crossing 51 states/DC and 14 years yields 663 potential observations, but these data limitations result in 495 observations per regression. While the resulting panel is unbalanced, we find similar results when keeping just the 26 states that have full employment history for all SE categories.

${ }^{19}$ The state-level controls are log population, log income per capita, log workforce size, the overall labor force participation rate among worker age groups, the overall unemployment rate, and the overall mean log weekly wage for full-time male workers with bachelor's educations or higher. We construct the latter four controls to mirror the SE outcome variables in Table 2. This helps to ensure our robustness to general changes in CPS sampling frames or variable definitions, although similar results are found without these controls.

${ }^{20}$ Unreported elasticities for citizen immigrant SE employment are 0.131 (0.091) and $0.044(0.133)$ with the LCA and Census dependencies, respectively. These elasticities confirm the concentrated impact of the H-1B reduced-form interaction on its primary population. They also suggest that previous immigrant SE workers are not being displaced by $\mathrm{H}-1 \mathrm{~B}$ workers.
} 
outcomes further reinforce the conclusion that native SE workers are not strongly affected. ${ }^{21}$

\subsection{City-Level Patenting Outcomes}

Tables 3 and 4 present our city-level patenting results using the LCA-based and Census-based dependencies, respectively. Estimations consider 281 cities over 1995-2007 for a total of 3653 observations. Column headers indicate dependent variables. We test for effects on the log level of city patenting for four ethnic groups in separate regressions: Indian, Chinese, AngloSaxon, and Other Ethnicity inventors. Other Ethnicity inventors include European, Hispanic, Japanese, Korean, Russian, and Vietnamese contributions. The fifth column considers log total patenting in the city.

Regressions again cluster standard errors cross-sectionally, this time by city. As our interaction term additionally relies on common annual variation from changes in $\mathrm{H}-1 \mathrm{~B}$ populations, we also tested clustering by year. These standard errors are substantially smaller than clustering cross-sectionally, and so we take the more conservative approach. We further tested the two-way clustering technique of Cameron et al. (2006), which returns results very similar to cross-sectional clustering.

The first column of Table 3 finds a positive relationship between increases in $\mathrm{H}-1 \mathrm{~B}$ visa allocations and Indian patenting in dependent cities. A 10\% increase in the $\mathrm{H}-1 \mathrm{~B}$ population is associated with a $3 \%$ increase in Indian patenting for each standard deviation growth in city dependency. Column 2 finds a slightly stronger relationship for Chinese invention. These elasticities are comparable to the CPS employment estimates for non-citizen immigrant SE workers in Table 2, a point to which we will return after viewing the full set of results.

Column 3 shows that the Other Ethnicity inventor group increases patenting in dependent cities, too. The elasticities, however, are less than half of the magnitude for Indian and Chinese inventors in Columns 1 and 2, and the linear differences are statistically significant. This confirms our expectations about the distribution of treatment effects of the H-1B program across different immigrant groups. Column 4 further finds that growth in inventors with Anglo-Saxon names in dependent cities is weakly responsive to shifts in $\mathrm{H}-1 \mathrm{~B}$ admissions. We estimate that a $10 \%$ increase in the $\mathrm{H}-1 \mathrm{~B}$ population is associated with a $0.5 \%$ increase in Anglo-Saxon invention

\footnotetext{
${ }^{21}$ Having viewed these results, we can comment further on our reduced-form estimation design. It was earlier mentioned that the reported $\beta$ coefficients do not recover the $\tilde{\beta}$ parameter from specification (1). Estimating this parameter would be advantageous and is the rationale for implementing a two-stage least squares (2SLS) model. In our patenting analyses, this is not feasible as we do not observe the endogenous regressor (i.e., $\left.\mathrm{H}_{-}-\mathrm{B}_{c, t}\right)$ by city or firm. A 2SLS model would potentially be feasible in Table 2 if we made the endogenous regressor the broader non-citizen immigrant SE population. The coefficients in Column 1 would be the first-stage estimations, and Columns 2-7 would be the reduced-form outcomes. The evident statistical power of both these components, however, shows that the resulting two-stage model would be imprecisely estimated.
} 
per standard deviation of city dependency. This elasticity is about a seventh of the magnitude estimated for Indian and Chinese inventors.

The final column finds a positive effect for total patenting. The weaker effect for total invention compared to Columns 1 and 2 is to be expected given that Indian and Chinese inventors comprise less than $15 \%$ of US domestic patenting during the period studied. The estimates suggest that a $10 \%$ growth in the $\mathrm{H}-1 \mathrm{~B}$ worker population is associated with a $0.7 \%$ increase in patenting per standard deviation of dependency. This elasticity is again comparable to the CPS estimate for the total SE employment growth by state.

The first row of Table 4 repeats this analysis with the Census-based dependency. The overall picture remains the same, especially the ordering across ethnicities. Elasticities with the Census-based dependency are smaller for all ethnicities, likely due to both a more conservative approach and greater measurement error in the estimated dependencies. This closely parallels the differences between Panels A and B of Table 2. The results for the growth in Anglo-Saxon and total invention are smaller, a pattern more suggestive of the H-1B program not having any effect on native inventors and a weak total impact.

The similar pattern of spatial effects in the ethnic patenting data and the CPS are comforting from a methodological perspective, as the patent data allow many more extensions that we turn to next. This comparability, although perhaps initially surprising, is also to be expected upon further reflection. We earlier noted that immigrant scientists and engineers are of comparable quality to natives, with their disproportionate impact for US science and engineering coming primarily through their more extensive training and employment in SE fields. This comparability is particularly emphasized by Hunt (2009). The estimations in Tables 2-4 simply show that the larger populations of these immigrants following $\mathrm{H}-1 \mathrm{~B}$ program expansions increase US invention through greater numbers of SE workers. To the extent that native scientists and engineers are not substantively affected by the program, total employment and invention also expand.

This perspective likewise addresses the fact that a substantial portion of $\mathrm{H}-1 \mathrm{~B}$ visa holders are not engaged in patenting activities. Many $\mathrm{H}-1 \mathrm{~B}$ workers, for example, are engaged in routine software coding and testing activities that do not result in patents. To this point, a number of $\mathrm{H}-1 \mathrm{~B}$ holders are also engaged in very advanced tasks like specialized mathematics that are innovative but not patentable. This frequent engagement in efforts other than patenting is a significant aspect of $\mathrm{H}-1 \mathrm{~B}$ employment, just as it is considerable among native SE workers. The program is important enough with respect to Indian and Chinese SE activity, however, that recent immigrants who do patent often hold an $\mathrm{H}-1 \mathrm{~B}$ visa at some stage of the immigration process. These workers may be hired directly from abroad on an H-1B, or they may be transitioning from school to work within the US. Both paths require a visa and are subject to the 
cap. Thus, increases in this overall population of immigrant SE workers can yield expansions of US invention and SE employment without the H-1B program specifically targeting patenting. ${ }^{22}$

\subsection{City-Level Robustness Analysis}

The remainder of Tables 3 and 4 present robustness checks on these basic findings. The linear framework (2) provides a parsimonious specification, but it is useful to examine effects throughout the dependency distribution. To do so, we first group cities into five quintiles of dependency, with each quintile containing 56 or 57 cities. We then generate three indicator variables (with notation $\left.I_{c}(\cdot)\right)$ for whether city $c$ is in the 3rd, 2nd, or most dependent quintiles of $\mathrm{H}-1 \mathrm{~B}$ dependency. The bottom two quintiles, which account for $40 \%$ of US cities but only $1 \%$ of LCA applications, serve as the reference group for measuring the effects on the top three quintiles.

Our extended estimating equation is

$$
\begin{aligned}
\ln \left(P A T_{c, t}\right)= & \phi_{c}+\eta_{t} \\
& +\beta_{1} \cdot\left[I_{c}(\text { Top Quintile }) \cdot \ln \left(\mathrm{H}-1 \mathrm{~B}_{t}\right)\right] \\
& +\beta_{2} \cdot\left[I_{c}(2 \text { nd Quintile }) \cdot \ln \left(\mathrm{H}-1 \mathrm{~B}_{t}\right)\right] \\
& +\beta_{3} \cdot\left[I_{c}(\text { rd Quintile }) \cdot \ln \left(\mathrm{H}-1 \mathrm{~B}_{t}\right)\right]+\epsilon_{c, t} .
\end{aligned}
$$

This flexible specification again tests whether innovation patterns in cities thought to be dependent upon $\mathrm{H}-1 \mathrm{~B}$ workers are more or less sensitive to changes in H-1B population levels. Considering the top three quintiles separately allows us to test for non-linear effects in the city distribution. The quintiles framework also tests whether our results are sensitive to the scale through which H-1B dependency is measured, as only the ordinal ranking of cities is used for grouping them. Said differently, in this approach we constrain the effects to be similar within the quintiles in specification (3). Main effects are again absorbed into the panel fixed effects.

Panel B of Tables 3 and 4 provide a consistent picture of treatment effects that grow with dependency. They suggest that the linear approach is not identifying off of the most extreme cases. They also provide assurance that the results are not being biased by a small group of cities or firms that exerts a substantial impact on admissions decisions and likewise receives disproportionate benefits. Effects are clearly strongest in the most dependent quintile, but the pattern of results looks similar in the second and third quintiles that we expect to have very

\footnotetext{
${ }^{22}$ Perhaps the more surprising finding is the comparable elasticities for Indian and Chinese invention. Even after considering Taiwan, Singapore, and related economies, the H-1B inflow of Chinese ethnicity SE workers is smaller relative to the overall population of Chinese inventors in the US than for Indian invention. Several factors likely lead to more equal elasticities, including a weaker propensity among marginal Indian H-1B holders to engage in patenting compared to Chinese holders. These results also might reflect crowding-in effects for other Chinese inventors. We find evidence for this latter effect in expansions of Chinese invention around technologies initially dominated by Indian inventors.
} 
little or no influence on H-1B admission choices. LCA applications are significantly skewed toward the upper quintile, suggesting that this is where the vast majority of political influence comes from. This is comforting as the evolution of the $\mathrm{H}-1 \mathrm{~B}$ program can reasonably be taken as exogenous outside of the top cities.

These quintile estimations also allow a second interpretation of the economic magnitudes of the results. A $10 \%$ growth in the national $\mathrm{H}-1 \mathrm{~B}$ population is associated with a $6 \%-12 \%$ growth in Indian and Chinese patenting in cities within the most dependent quintile relative to the control group. The corresponding impact for total invention is $0 \%-2 \%$. The growth effect in the second and third quintiles is 3\%-8\% for Indian and Chinese patenting, with total invention expanding by $1 \%$ or less.

Panel C returns to the linear specification to test controlling for additional labor market characteristics. It is natural to worry whether the reduced-form interactions in (2) are capturing other heterogeneity across cities than H-1B dependency or other time effects than the aggregate shifts in $\mathrm{H}-1 \mathrm{~B}$ admissions. The ordering of elasticities across ethnicities provides helpful assurance in the story presented, as other explanations must similarly explain localized treatment effects among Indian and Chinese inventors.

Panel $\mathrm{C}$ incorporates more explicit controls. Analogous to Table 2, we first include the log of the population and income per capita of the city as regressors. We also include region-year fixed effects to control for broader trend differences across the nine Census regions since 1995. These regional controls are easily extended to state-year fixed effects, but the broader groupings provide a more consistent number of cities per grouping. Finally, Figures 2 and 3 highlight that Indian and Chinese inventors are more concentrated in high-tech sectors than other ethnic groups. Differences in sectoral growth rates or changing propensities to seek patents may consequently impact our findings. We thus include measures of expected city-level patenting for each ethnic inventor group based on national patenting trends and pre-period city technology specializations. $^{23}$

When we introduce these strict controls, the relative ordering of treatment effects remains the same as in Panel A. The elasticities uniformly decrease in economic magnitude, while the standard errors remain constant. These estimates find that a $10 \%$ increase in the $\mathrm{H}$ $1 \mathrm{~B}$ population increased Indian and Chinese invention by $1 \%-2 \%$ per standard deviation of

\footnotetext{
${ }^{23}$ We construct our expected patenting measures by first calculating the mean annual patenting done in the focal city by each ethnic group over 1990-1995 in 36 technology sectors. These sectors are the sub-categories of patent classifications; examples include "Resins", "Computer Peripherals", and "Optics." We then take subsequent growth in national patenting for each sector, weight these trends by the city's pre-period composition, and sum across technologies. To maintain a consistent specification and to maximize explanatory power, we include the expected patenting trends for all four ethnic groups in each estimation. Each ethnicity is particularly dependent on the expected trend for its own ethnicity. Chinese inventors also experience large increases in cities with strong expected Indian patenting growth in the IT sector.
} 
dependency. Effects for Anglo-Saxon inventors are not statistically different from zero for either dependency measure, while total invention is estimated to have increased by about $0.5 \%$ per standard deviation of dependency.

Continuing with this extended regression, Panel D excludes from the sample patents related to Computers and Communications (USPTO category 2). The H-1B program is closely linked to the development of the IT sector and grew strongly during the 1990s high-tech boom period. Beyond the expected technology trends included in Panel $\mathrm{C}$, this regression further tests whether patents from the computer sector and neighboring fields are solely driving the observed relationships. Although the coefficient estimates are somewhat smaller, the qualitative findings are in general quite comparable.

Our earlier working paper reports a number of additional robustness checks. We first substitute a six-year summation of the annual H-1B visa cap in place of Lowell's H-1B population estimates for $\mathrm{H}_{-}-1 \mathrm{~B}_{t}$. The cap summation introduces more measurement error into the $\mathrm{H}-1 \mathrm{~B}$ population estimate, but it perhaps benefits from stronger exogeneity. The results are very similar with this alternative estimation, since the cap has been binding or close to binding in most years. Generally, the modelling choice of $\mathrm{H}-1 \mathrm{~B}_{t}$ is of second-order importance to the dependency measure employed for cities.

Comparable results are also found when excluding the West Coast, when testing before and after 2001, and when excluding recent patent applications. We find similar effects when using first-differenced specifications, although autoregressive tests of error terms suggest that levels specifications are more appropriate. Importantly, the findings also hold when introducing additional interaction terms focused on city populations or growth in US citizen immigrant SEs. Our main estimations recode counts of less than one ethnic patent for a given city-year observation to be equal to one ethnic patent. We do so under the claim that is not meaningful to distinguish between zero and one Indian or Chinese patent for a city. This is merely done to maintain consistent sample sizes, and the elasticity estimates are similar when we instead exclude zero-valued cells.

We further performed estimations that drop all patents associated with 307 of the most highly-dependent firms that we could identify. These firms account for $30 \%$ of patents during 1995-2006 and are discussed in more detail in Section 5. This grouping includes the most frequent LCA applicants and the largest US patentors. Our results are robust to this technique, confirming that the important effects estimated for the second quintile are not due to a few influential firms patenting in several cities. We also find similar coefficients for the top quintile when dropping the 20 most dependent cities of this group, suggesting again that the results extend deeper than the extreme cases like San Francisco and Boston. 
One limitation of our approach, however, is important to note. Our econometric specifications are motivated by empirical studies finding that contemporaneous R\&D investments have the most important impact for rates of technology formation (e.g., Pakes and Griliches 1980, Hausman et al. 1984, Hall et al. 1986). In the context of this paper, we consider how recent investments in hiring high-skilled immigrants affect innovation. When looking at dynamic specifications that introduce leads and lags on the observed $\mathrm{H}-1 \mathrm{~B}$ population, however, the patterns are mixed. We often find contemporaneous effects to be the most important, but the patterns are unfortunately too sensitive to specification choices or included time periods to draw conclusions. Thus, while our interaction approach can measure cross-sectional sensitivity to longitudinal program changes, it cannot identify the precise timing from $\mathrm{H}-1 \mathrm{~B}$ population adjustments to patenting outcomes. ${ }^{24}$

\subsection{Comparison to Canadian Cities}

Canadian cities provide a useful baseline for comparing the estimated effects of the $\mathrm{H}-1 \mathrm{~B}$ program on US ethnic invention patterns. Indian and Chinese inventors account for about $15 \%$ of Canada's patents during the 1995-2007 period, only slightly more than in the US, and the technology breakdowns are similar for the two countries. We therefore test whether Canadian cities display similar or different trends in innovation relative to those found in the US. Identical trends in Canada and America would warn that our estimates are biased by other secular changes (e.g., greater Indian and Chinese immigration to North America interacting with past immigrant networks).

Many Canadian inventors seek patent protection from the USPTO. Using over 200,000 granted patents and non-overlapping applications filed from Canada, we estimate the ethnic composition of Canadian inventors in metropolitan areas that are comparable in size and scope to the US Metropolitan Statistical Areas through which we define US cities. Likewise, we use the 1991 Canadian Census of Populations (IPUMS) to construct non-citizen immigrant SE dependency metrics roughly similar to our Census-based metrics for the US. We are able to construct city-level dependencies for 22 cities, with Toronto and Vancouver being the most dependent major Canadian cities. We unfortunately do not have an equivalent to the LCA data set for Canada.

\footnotetext{
${ }^{24}$ These lag structure limitations are due to both data constraints and economic reasons. Perhaps the most important issue is a shift in occupations using H-1B visas that occurred in the mid 1990s (e.g., Hira 2004). The share of $\mathrm{H}-1 \mathrm{~B}$ visas granted to healthcare and therapy occupations declined from $54 \%$ in 1995 to $14 \%$ in 1998 . $\mathrm{SE}$ and computer specialist occupations grew from $25 \%$ to about $60 \%$ during this same period, and the SE sector has been dominant since this inversion. Our main estimations are robust to whether we use Lowell's total H-1B populations, six-year summations of the H-1B cap, or attempt to adjust for occupational shifts. These modelling choices, however, can substantively influence lag structure analyses.
} 
Panel E of Table 4 presents the placebo experiment using the Canadian sample of cities. We regress ethnic patenting in Canadian cities against each city's non-citizen immigrant SE dependency interacted with the log of the US H-1B population. As in Panel A, these regressions include city and year fixed effects. None of the results are significantly different than zero, and the point estimates are small in economic magnitude. Extensions of this placebo analysis, such as estimating a variant of specification (3), find similar results.

The null results are reassuring for our empirical design. They suggest that our findings for the US are not being driven by unmodeled secular changes that also impacted Canada. Such secular trends could include, for example, globalization and the rapid economic development of India and China. As the technology fields of Indian and Chinese inventors are similar in Canada and America, many industry cycles are also captured. Of course, this Canadian analysis will not capture unmodeled secular trends exclusive to the US.

\section{Firm-Level Analyses of the H-1B Program}

We extend our city-level results with a firm-level analysis that exploits additional detail that is possible with the ethnic patenting data. Substantial heterogeneity exists across firms in ethnic invention, and this variation allows us to characterize the impacts of $\mathrm{H}-1 \mathrm{~B}$ visa changes in an alternative way. This is the first large scale description of ethnic invention within firms and the first analysis of the link between immigration and innovation at the firm level of which we are aware. We focus on 77 major patenting firms that are likely to be influenced by high-skilled immigration. These firms are all publicly listed, headquartered in the US, have at least four patents per year, and have measurable ethnic patenting. They account for a quarter of all US patenting during the 1995-2007 period. ${ }^{25}$

Table 5 details the general characteristics of this sample. The firms have over 345 patents on average per year, and the ethnicity and geography of inventors in these firms broadly match US aggregates. A comparison of the means and medians across these different technology categories and regions also demonstrates that firms tend to specialize in particular types of innovation and to spatially cluster their innovations. Although sampled firms are generally quite large, substantial variation exists in sales, employees, R\&D expenditures, and LCA applications. Unreported regressions find that larger firms and high-tech firms tend to have higher shares of Indian and

\footnotetext{
${ }^{25}$ Our sample construction involved two steps. We first identified 592 unique firms that met one of three criteria: (1) firms included in two lists of top H-1B sponsors for 1999 and 2006 (the only two lists for our sample period); (2) firms accounting for $0.05 \%$ or more of patent grants or applications during 2001-2004; and (3) firms accounting for $0.03 \%$ or more of LCA applications during 2001-2006. Of these 592 firms, 307 have at least one patent during the sample period. We then made additional restrictions on the firm being publicly listed and having ethnic patenting in each year to facilitate an intensive margin analysis of patenting. We find similar results when using an unbalanced panel built off of the larger sample. We document the sample construction in extensive detail in our earlier working paper.
} 
Chinese inventors. Firms undertaking most of their innovative activity in the Middle Atlantic and West Coast regions also have higher average shares of ethnic inventors. Among these employers, technology focus and regional location explain more of the variation in ethnic inventor compositions than firm size.

In order to understand the effects of different admissions levels on firms, we consider a specification similar to the linear approach (2) employed in the city analysis. We measure H-1B dependency through each firm's 2001-2002 LCA filings normalized by Compustat employment. We again interact this dependency with the national H-1B population estimate. Regressions include panel fixed effects and cluster standard errors cross-sectionally by firm.

Table 6 presents the firm-level findings. Panel A finds that ethnic invention, and Indian invention in particular, is closely tied to $\mathrm{H}-1 \mathrm{~B}$ admissions levels. A $10 \%$ growth in $\mathrm{H}-1 \mathrm{~B}$ admissions correlates with an 4\%-5\% growth in Indian invention for each standard deviation increase in dependency. The program is linked to a $3 \%$ higher growth in total invention per standard deviation increase in dependency. These results point to particularly powerful impacts for heavily influenced firms among major patenting firms.

Panel B extends the estimation to include a firm-specific measure of expected patenting. This measure is based on pre-period technology specializations and national patenting trends. Unlike before, however, we do not construct ethnic-specific technology trends given the limited preperiod data for many firms. We also include region-sector-year fixed effects. We define regions through the four Census regions and sectors through patent categories. On both dimensions, firms are classified by where they patent the most during the sample period. These fixed effects remove annual trends common to a sector and region, such as the growth of the computeroriented sector on the West Coast. The patterns are very similar in this extended regression.

Panel C finally tests for heightened sensitivity in the computer-oriented sector where the $\mathrm{H}$ 1B program has been very influential. Continuing with the extended specification in Panel B, we interact the core regressor with an indicator variable for the computer and communications patent category. We demean both regressors before interaction to restore main effects, and the main effect for the computer-oriented sector is absorbed by the region-sector-year fixed effects. The base effects find a similar pattern excepting the weaker role of Chinese inventors. The interactions suggest that Indian and Chinese responses are particularly strong in the computeroriented sector.

We consider this firm-level analysis as a nice robustness check on the city-level and statelevel approaches. It provides microeconomic evidence in support of the labor market results, and it quantifies the claims of high-tech executives that their firms are especially vulnerable to high-skilled immigration policies for temporary workers. As some of our 77 firms are among the 
primary lobbyists for H-1B legislation, however, these results should be interpreted as partial correlations only.

\section{Conclusion}

Over the last fifteen years, the $\mathrm{H}-1 \mathrm{~B}$ visa program for temporary workers has played a significant role in US innovation. As immigrants are especially important for US innovation and technology commercialization, this makes the $\mathrm{H}-1 \mathrm{~B}$ program a matter of significant policy importance. We find that fluctuations in $\mathrm{H}-1 \mathrm{~B}$ admissions significantly influenced the rate of Indian and Chinese patenting in cities and firms dependent upon the program relative to their peers. Most specifications find limited effects for native SE employment or patenting. We are able to rule out displacement effects, and small crowding-in effects may exist. We conclude that total invention increased with higher admissions primarily through the direct contributions of immigrant inventors.

We close with four related research questions that we hope can be addressed in future work. First, we have focused exclusively on the H-1B program given its particular importance in science and engineering and large admissions fluctuations. We hope that future research will consider other temporary visa categories. The H-1B program has unique characteristics, and quantifying the impacts of other visa programs will clarify whether our results apply generally or are due to particular features of the H-1B program. For example, the prevailing wage requirement may limit adverse effects for natives to the extent that the requirement is followed. Likewise, the manner in which $\mathrm{H}-1 \mathrm{~B}$ workers are tied to their sponsoring firms may produce special outcomes. Such comparative assessments will also aid policy makers when crafting future immigration policies.

Second, our analysis considers high-frequency variation since 1995, and we cannot quantify long-run impacts of these policy choices as a consequence. Given the time and expense involved in training new SE workers, long-run effects may be different. Fluctuations in the H-1B cap are quite recent, so researchers will need to unite our work with studies exploiting low-frequency variation to understand these dynamics. It is also important for future research to extend beyond area-based studies to analyze variations across alternative dimensions like occupations and industries. These complementary approaches will help assess likely effects at the national level and would further inform future theoretical work on how the supply side of innovation influences overall US technology growth. ${ }^{26}$

\footnotetext{
${ }^{26}$ We earlier noted general mechanisms that are likely to exist regardless of approach (e.g., increased supply of knowledge, complementarities). We also noted that agglomeration economies are likely to play an important role in spatial analyses. Future work should evaluate whether relevant agglomeration economies are stronger
} 
Third, our analysis quantifies patenting growth due to higher H-1B admission rates for cities and firms. There are many different types of research organizations: universities, government labs, private inventors, and others. We have not analyzed how changes in the $\mathrm{H}-1 \mathrm{~B}$ program alter the local relationships among these different institutions. For example, the comparative advantage that universities have had for obtaining H-1B visas since 2001 may result in greater dependencies of local industry on universities for certain forms of SE advancement. Understanding these local inter-linkages will be informative for both H-1B program assessments and of general interest for technology transfer studies.

Finally, although ethnic patenting data allows us to characterize the role of $\mathrm{H}-1 \mathrm{~B}$ workers for US innovation and SE employment in a unique way, we recognize that the $\mathrm{H}-1 \mathrm{~B}$ program impacts other aspects of the US economy. About half of the major employers of H-1B visas that we identified for potential inclusion in our firm sample did not file for a patent during our period of study. Future research should quantify the economic impacts for other sectors like accounting and consulting firms, banks and financial institutions, and public services in ways that are appropriate for these sectors. It will likewise be particularly interesting to quantify job creation or displacement effects for occupations other than inventors among high-tech firms.

\section{References}

[1] Acemoglu, Daron, and Joshua Linn, "Market Size in Innovation: Theory and Evidence from the Pharmaceutical Industry", The Quarterly Journal of Economics 119 (2004), 1049-1090.

[2] Agrawal, Ajay, Devesh Kapur, and John McHale, "How do Spatial and Social Proximity Influence Knowledge Flows? Evidence from Patent Data", Journal of Urban Economics 64 (2008), 258-269.

[3] Barro, Robert, and Xavier Sala-i-Martin, Economic Growth (Cambridge: MIT Press, 1995).

[4] Borjas, George, "Economics of Immigration", Journal of Economic Literature 32 (1994), 1667-1717.

[5] Borjas, George, "The Labor Demand Curve Is Downward Sloping: Reexamining the Impact of Immigration on the Labor Market", The Quarterly Journal of Economics 118:4 (2003), 1335-1374.

[6] Borjas, George, "Do Foreign Students Crowd Out Native Students from Graduate Programs?", in Ehrenberg, Ronald, and Paula Stephan (ed.), Science and the University (Madison, WI: University of Wisconsin Press, 2005).

[7] Borjas, George, "Immigration in High-Skill Labor Markets: The Impact of Foreign Students on the Earnings of Doctorates", NBER Working Paper 12085 (2006).

or weaker at the national level. Some agglomeration rationales like labor pooling would suggest that city-level effects would be stronger. We note, however, that current concerns over higher rates of return SE migration to India and China focus on a loss of US technology leadership. The fear is less about losing individual scientists than losing the critical mass of frontier scientists, a process that would depend upon significant country-level agglomeration economies. 
[8] Cameron, Colin, Jonah Gelbach, and Douglas Miller, "Robust Inference with Multi-way Clustering", Working Paper (2006).

[9] Card, David, "Immigrant Inflows, Native Outflows, and the Local Labor Market Impacts of Higher Immigration", Journal of Labor Economics 19:1 (2001), 22-64.

[10] Chellaraj, Gnanaraj, Keith Maskus, and Aaditya Mattoo, "The Contribution of Skilled Immigrations and International Graduate Students to U.S. Innovation", Review of International Economics 16:3 (2008), 444-462.

[11] Ellison, Glenn, Edward Glaeser, and William Kerr, "What Causes Industry Agglomeration? Evidence from Coagglomeration Patterns", forthcoming in American Economic Review (2009).

[12] Facchini, Giovanni, Anna Maria Mayda, and Prachi Mishra, "Do Interest Groups Affect Immigration Policy?", Working Paper (2008).

[13] Foley, C. Fritz, and William Kerr, "U.S. Ethnic Scientists and Foreign Direct Investment Placement", Working Paper (2008).

[14] Freeman, Richard, The Market for College-Trained Manpower: A Study in the Economics of Career Choice (Cambridge, MA: Harvard University Press, 1971).

[15] Freeman, Richard, "People Flows in Globalization", Journal of Economic Perspectives 20:2 (2006), 145-170.

[16] Friedberg, Rachel, and Jennifer Hunt, "The Impact of Immigrants on Host Country Wages, Employment and Growth", Journal of Economic Perspectives 9:2 (1995), 23-44.

[17] Furman, Jeffrey, Michael Porter, and Scott Stern, "The Determinants of National Innovative Capacity", Research Policy 31 (2002), 899-933.

[18] Glaeser, Edward, and William Kerr, "Local Industrial Conditions and Entrepreneurship: How Much of the Spatial Distribution Can We Explain?", Journal of Economics and Management Strategy 18:3 (2009), 623-663.

[19] Griliches, Zvi, "Patent Statistics as Economic Indicators: A Survey", Journal of Economic Literature 28:4 (1990), 1661-1707.

[20] Hall, Bronwyn, Zvi Griliches, and Jerry Hausman, "Patents and R and D: Is There a Lag?", International Economic Review 27 (1986), 265-283.

[21] Hall, Bronwyn, Adam Jaffe, and Manuel Trajtenberg, "The NBER Patent Citation Data File: Lessons, Insights and Methodological Tools", NBER Working Paper 8498 (2001).

[22] Hausman, Jerry, Bronwyn Hall, and Zvi Griliches, "Econometric Models for Count Data with an Application to the Patents-R\&D Relationship", Econometrica 52 (1984), 909-938.

[23] Hira, Ron, "U.S. Immigration Regulations and India's Information Technology Industry", Technological Forecasting 6 Social Change 71 (2004), 837-854.

[24] Hunt, Jennifer, "Which Immigrants are Most Innovative and Entrepreneurial? Distinctions by Entry Visa", NBER Working Paper 14920 (2009). 
[25] Hunt, Jennifer, and Marjolaine Gauthier-Loiselle, "How Much Does Immigration Boost Innovation?", forthcoming in American Economic Journal: Macroeconomics (2008).

[26] Kannankutty, Nirmala, "Unemployment Rate of U.S. Scientists and Engineers Drops to Record Low 2.5\% in 2006", NSF SRS Info Brief (2008).

[27] Kerr, Sari, and William Kerr, "Economic Impacts of Immigration: A Survey", HBS Working Paper 09-013 (2008).

[28] Kerr, William, "The Ethnic Composition of US Inventors", HBS Working Paper 08-006 (2007).

[29] Kerr, William, "Ethnic Scientific Communities and International Technology Diffusion", Review of Economics and Statistics 90:3 (2008), 518-537.

[30] Kerr, William, "The Agglomeration of US Ethnic Inventors", in Edward Glaeser (ed.) Economics of Agglomeration (2009).

[31] Kirkegaard, Jacob, "Outsourcing and Skill Imports: Foreign High-Skilled Workers on H$1 \mathrm{~B}$ and L-1 Visas in the United States", Peterson Institute for International Economics Working Paper 05-15, (2005).

[32] Lemieux, Thomas, "The Changing Nature of Wage Inequality", NBER Working Paper 13523 (2007).

[33] Lowell, B. Lindsay, "H-1B Temporary Workers: Estimating the Population", The Center for Comparative Immigration Studies Working Paper 12 (2000).

[34] Lowell, B. Lindsay, "Skilled Temporary and Permanent Immigrants in the United States", Population Research and Policy Review 20:1-2 (2001).

[35] Lowell, B. Lindsay, and Bryan Christian, "The Characteristics of Employers of H-1Bs", Institute for the Study of International Migration Working Paper (2000).

[36] Lowell, B. Lindsay, and Hal Salzman, "Into the Eye of the Storm: Assessing the Evidence on Science and Engineering Education, Quality, and Workforce Demand", Working Paper (2007).

[37] Matloff, Norman, "On the Need for Reform of the H-1B Non-Immigrant Work Visa in Computer-Related Occupations", University of Michigan Journal of Law Reform (2003).

[38] Matloff, Norman, "Needed Reform for the H-1B and L-1 Work Visas (and Relation to Offshoring)", Working Paper (2004).

[39] Miano, John, "The Bottom of the Pay Scale: Wages for H-1B Computer Programmers", CIS Backgrounder (2005).

[40] Miano, John, "H-1B Visa Numbers: No Relationship to Economic Need", CIS Backgrounder (2008).

[41] Mithas, Sunil, and Henry Lucas, "Does High-Skill Immigration Make Everyone Better Off? United States' Visa Policies and Compensation of Information Technology Professionals", Working Paper (2009).

[42] NFAP Policy Brief, "H-1B Visas and Job Creation", Arlington, VA (2008). 
[43] Pakes, Ariel and Zvi Griliches "Patents and R\&D at the Firm Level: A First Look", Economics Letters 5 (1980), 377-381.

[44] Peri, Giovanni, "Higher Education, Innovation and Growth", in Giorgio Brunello, Pietro Garibaldi, and Etienne Wasmer (eds.) Education and Training in Europe (Oxford: Oxford University Press, 2007).

[45] Reksulak, Michael, William Shughart, and Gokhan Karahan, "Barrier to Entry: The Political Economy of H-1B Visas", University of Mississippi Working Paper (2006).

[46] Rivera-Batiz, Luis and Paul Romer, "Economic Integration and Endogenous Growth", The Quarterly Journal of Economics 106:2 (1991), 531-555.

[47] Rosenthal, Stuart, and William Strange, "The Determinants of Agglomeration", Journal of Urban Economics 50 (2001), 191-229.

[48] Ryoo, Jaewoo, and Sherwin Rosen, "The Engineering Labor Market", Journal of Political Economy 112:2 (2004), S110-S140.

[49] Saxenian, AnnaLee, "Silicon Valley's New Immigrant High-Growth Entrepreneurs", Economic Development Quarterly 16:1 (2002), 20-31.

[50] Siow, Aloysius, "Occupational Choice under Uncertainty", Econometrica 52 (1984), 631645.

[51] Stephan, Paula, and Sharon Levin, "Exceptional Contributions to US Science by the Foreign-Born and Foreign-Educated", Population Research and Policy Review 20:1 (2001), 59-79.

[52] Tambe, Prassana, and Lorin Hitt, "H-1B Visas, Offshoring, and the Wage of US Information Technology Workers", Working Paper (2009).

[53] United States Citizenship and Immigration Services, "Characteristics of Specialty Occupation Workers (H-1B)", Washington DC (1998-2006).

[54] United States Citizenship and Immigration Services, "H-1B Benefit Fraud \& Compliance Assessment", Washington DC (2008).

[55] Wadhwa, Vivek, AnnaLee Saxenian, Ben Rissing, and Gary Gereffi, "America's New Immigrant Entrepreneurs I", Working Paper (2007).

[56] Zavodny, Madeline, "The H-1B Program and its Effects on Information Technology Workers", Federal Reserve Bank of Atlanta Economic Review (2003). 
Fig. 1: Growth in US Ethnic Patenting

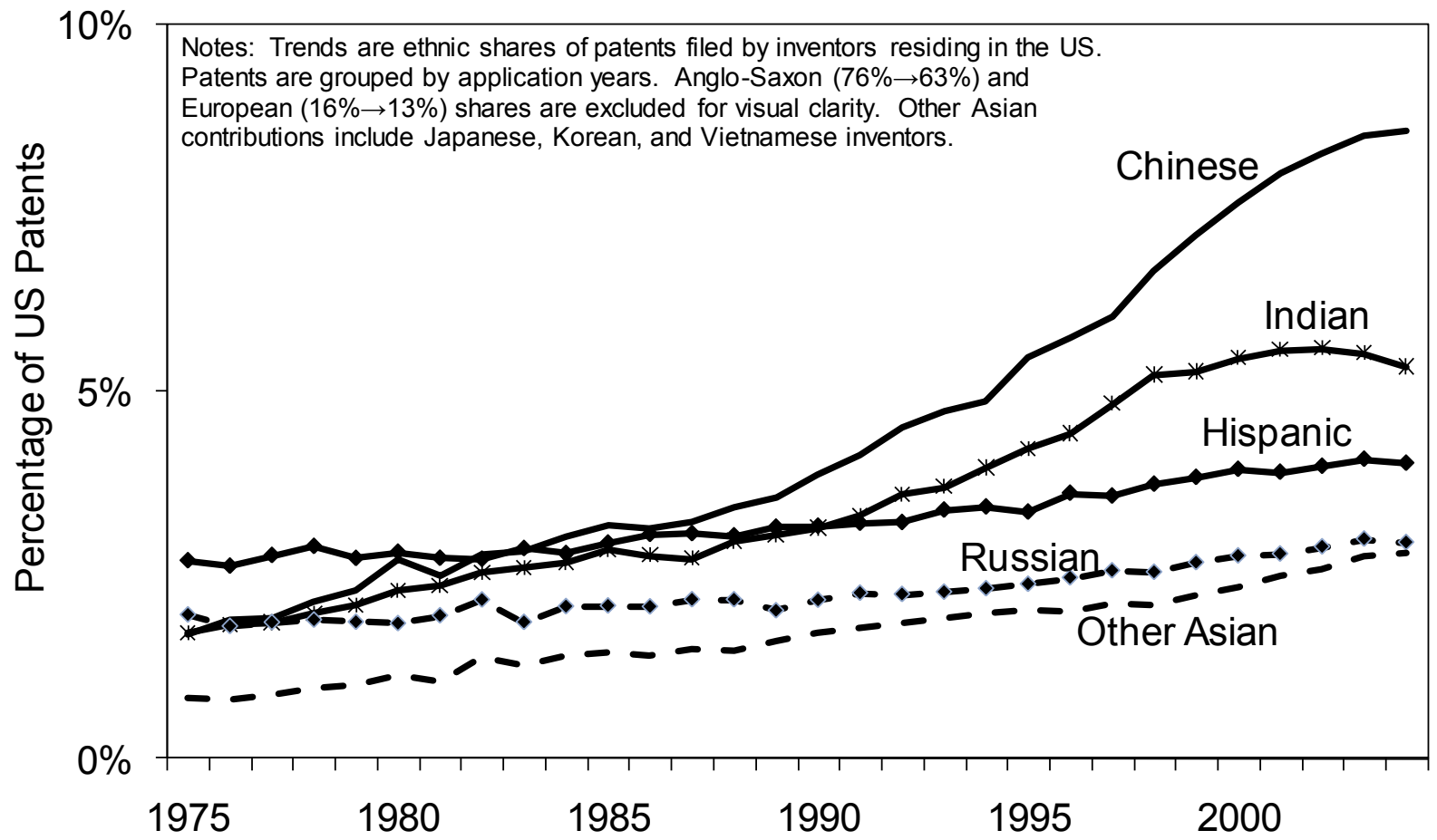

Fig. 2: Indian Contributions by Technology

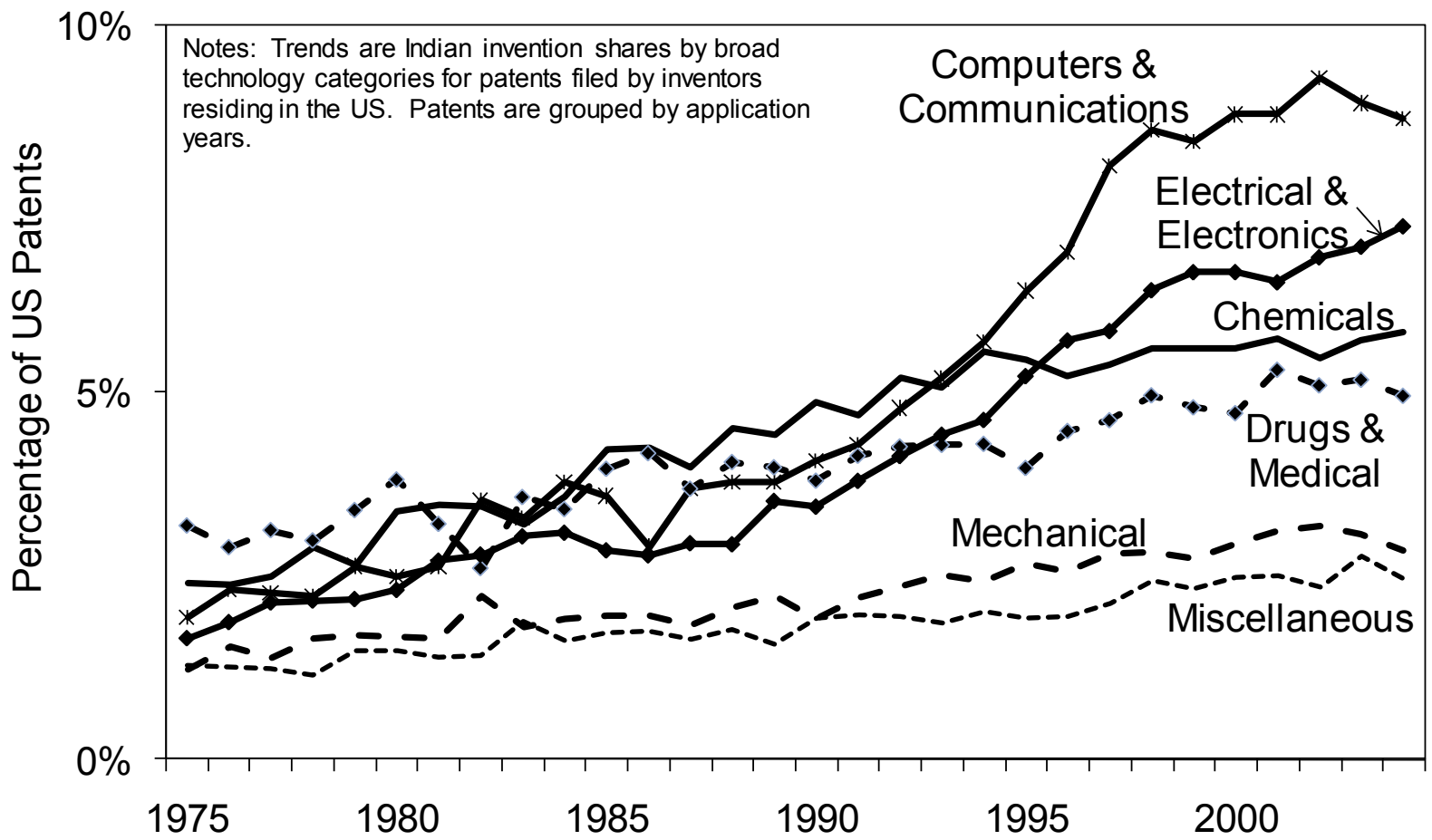


Fig. 3: Chinese Contributions by Technology

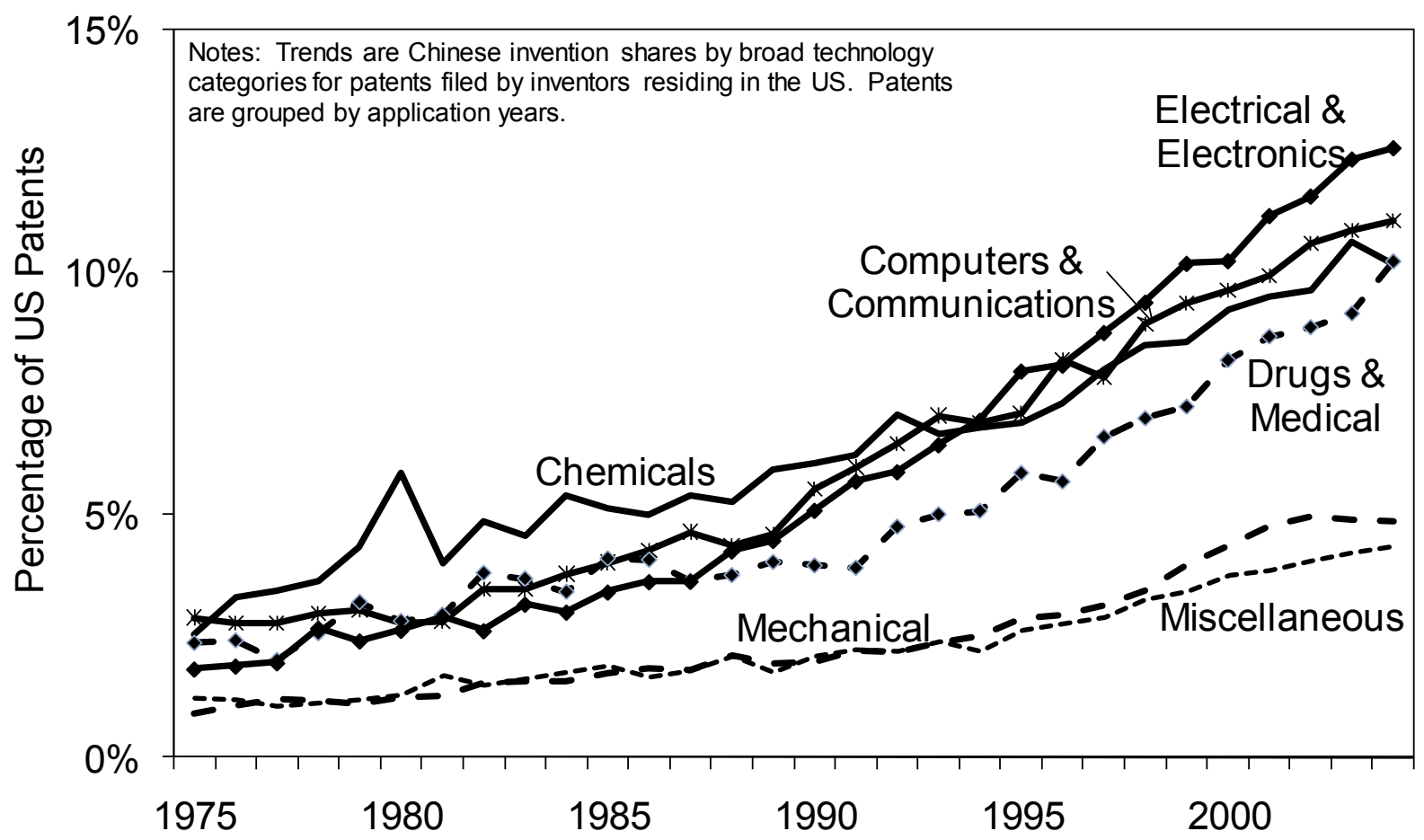

Fig. 4: H-1B Visas and Population Estimates

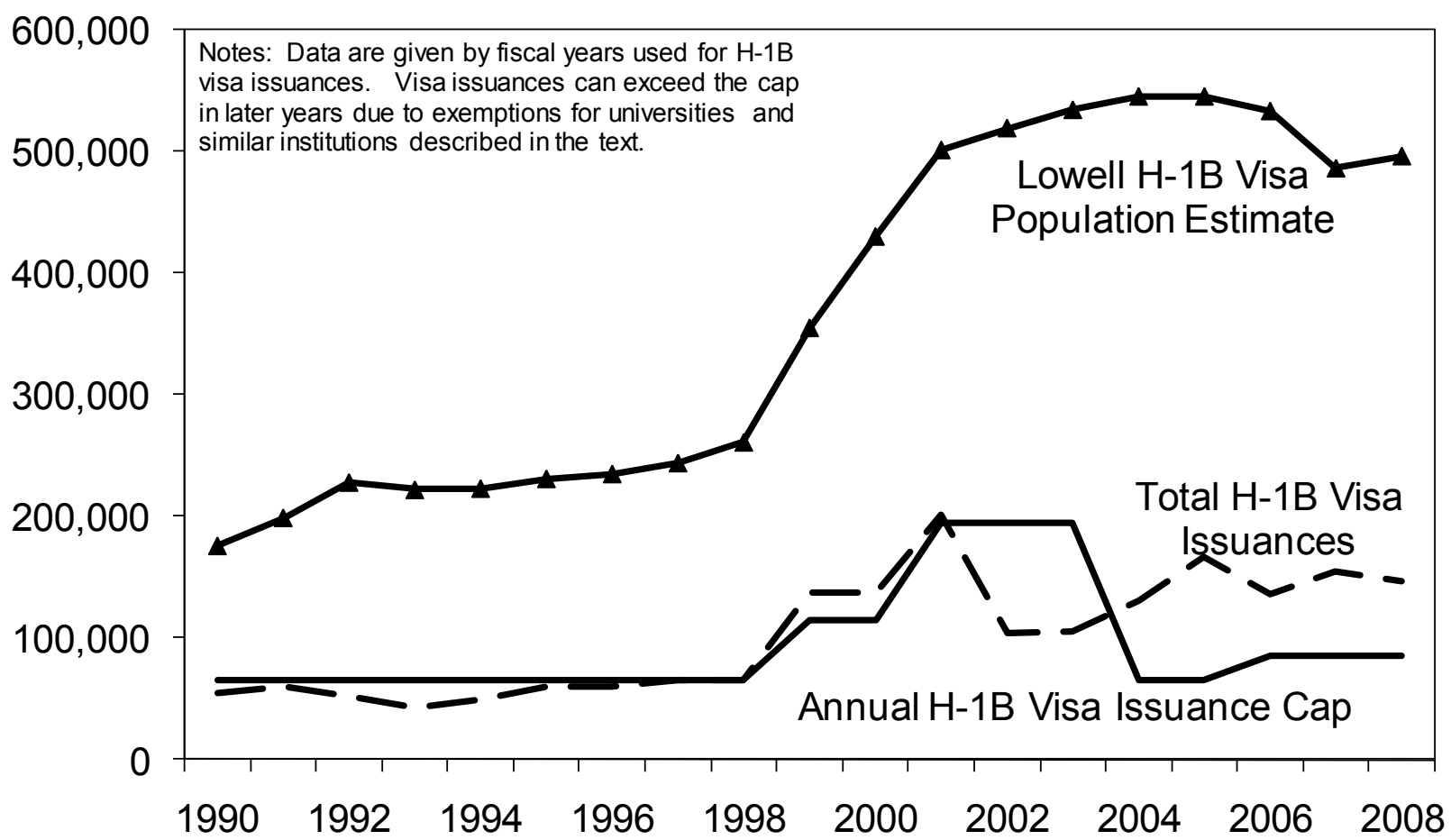


Table 1: Most Dependent Cities and States on H-1B Program

\begin{tabular}{|c|c|c|c|c|}
\hline & $\begin{array}{c}\text { LCA-Based Dependency } \\
\text { 2001-2002 LCA Filings for } \\
\text { H-1B Visas Per Capita (x1000) }\end{array}$ & & $\begin{array}{l}\text { Census-Based Dependency } \\
1990 \text { Non-Citizen Immigrant SE } \\
\text { Workforce per Capita (x1000) }\end{array}$ & \\
\hline & $(1)$ & & $(2)$ & \\
\hline \multicolumn{5}{|c|}{ A. Most Dependent Cities } \\
\hline$\# 1$ & San Francisco, CA & 8.323 & Lafayette-W. Lafayette, IN & 7.810 \\
\hline \#2 & Miami, FL & 5.502 & Bryan-College Station, TX & 5.571 \\
\hline$\# 3$ & Washington, DC & 5.430 & San Francisco, CA & 5.096 \\
\hline \#4 & Raleigh-Durham, NC & 5.220 & Columbia, MO & 4.462 \\
\hline$\# 5$ & Boston, MA & 5.149 & Gainesville, FL & 4.146 \\
\hline \#6 & Austin, TX & 4.897 & Champaign-Urbana-Rantoul, IL & 4.023 \\
\hline$\# 7$ & New York, NY & 4.777 & Washington, DC & 3.168 \\
\hline$\# 8$ & Burlington, VT & 4.491 & Boston, MA & 3.129 \\
\hline$\# 9$ & Atlanta, GA & 4.116 & Raleigh-Durham, NC & 2.723 \\
\hline$\# 10$ & Dallas-Fort Worth, TX & 3.943 & Los Angeles, CA & 2.288 \\
\hline \#11 & Champaign-Urbana-Rantoul, IL & 3.819 & Rochester, MN & 2.247 \\
\hline$\# 12$ & Iowa City, IA & 3.804 & New York, NY & 2.185 \\
\hline$\# 13$ & Houston, TX & 3.712 & Houston, TX & 2.156 \\
\hline \#14 & Bryan-College Station, TX & 3.577 & Spokane, WA & 2.078 \\
\hline$\# 15$ & Seattle, WA & 3.393 & State College, PA & 2.058 \\
\hline \multicolumn{5}{|c|}{ B. Most Dependent States } \\
\hline$\# 1$ & District of Columbia & 9.829 & New Jersey & 2.491 \\
\hline$\# 2$ & New Jersey & 4.013 & California & 2.455 \\
\hline \#3 & Massachusetts & 4.005 & Massachusetts & 2.056 \\
\hline$\# 4$ & California & 3.502 & District of Columbia & 2.012 \\
\hline$\# 5$ & New York & 3.366 & Maryland & 1.884 \\
\hline$\# 6$ & Connecticut & 2.804 & New York & 1.485 \\
\hline \#7 & Delaware & 2.526 & Delaware & 1.395 \\
\hline$\# 8$ & Maryland & 2.277 & Connecticut & 1.092 \\
\hline$\# 9$ & Florida & 2.183 & Texas & 1.047 \\
\hline$\# 10$ & Texas & 2.116 & Virginia & 1.014 \\
\hline \#11 & Virginia & 2.113 & Michigan & 0.976 \\
\hline$\# 12$ & Georgia & 1.974 & New Hampshire & 0.967 \\
\hline$\# 13$ & Washington & 1.937 & Illinois & 0.963 \\
\hline$\# 14$ & Illinois & 1.868 & Washington & 0.890 \\
\hline$\# 15$ & Michigan & 1.673 & Hawaii & 0.832 \\
\hline
\end{tabular}

Notes: Table presents largest dependencies on the H-1B program by city and state. Dependency in Column 1 is measured as the sum of Labor Condition Applications (LCAs) over 2001-2002 normalized by population. These applications are an initial step for obtaining an H-1B visa. Dependency in Column 2 is measured as non-citizen scientists and engineers per capita in the 1990 Census. Non-citizens include temporary visa holders (e.g., H-1B) and permanent residents. Both dependencies are multiplied by 1000 for presentation purposes. Washington, DC, in Panel A differs from the District of Columbia in Panel B as the former includes metropolitan areas in Virginia and Maryland. 
Table 2: State-Year Regressions of H-1B Program Dependency and Science and Engineering Employment

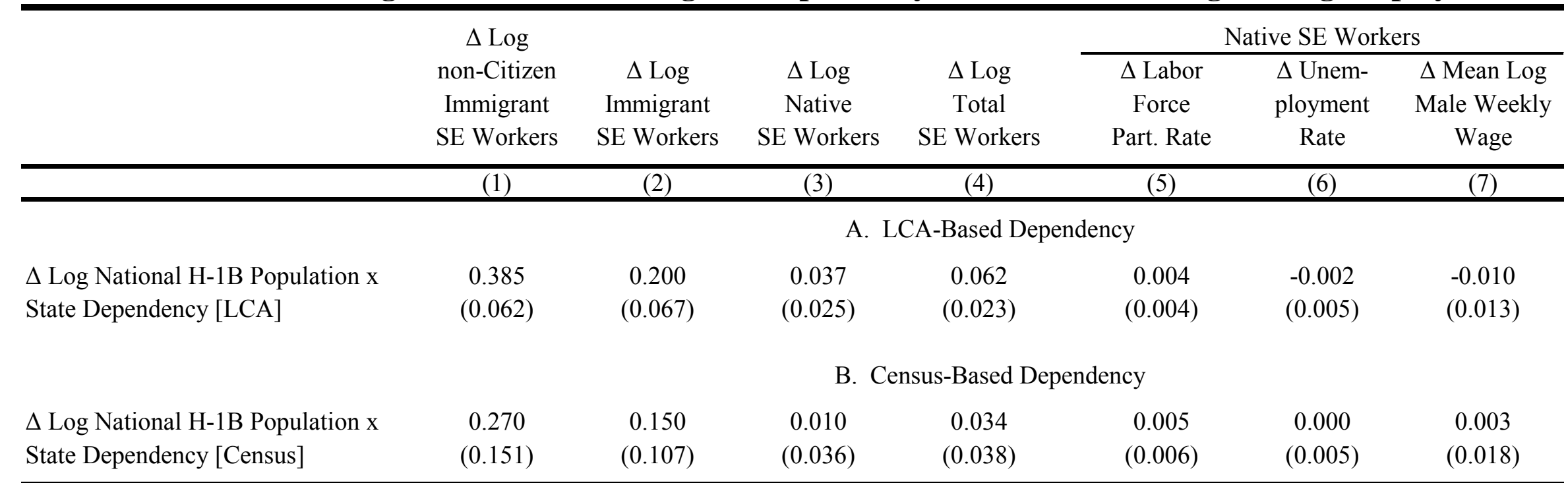

Notes: State-year regressions estimate the effect of changes in the national H-1B population over 1995-2008 for science and engineering (SE) workforces by state using the Current Population Survey (CPS). The annual H-1B population regressor is interacted with state-level dependencies. Dependency in Panel A is measured through LCA applications in 2001-2002 divided by state populations. Dependency in Panel B is measured through non-citizen immigrant SE workforces in the 1990 Census divided by state populations. Dependencies are normalized to have unit standard deviation before interacting. First-differenced specifications are utilized due to the redesign of the CPS in 2003; changes from 2002-2003 are excluded. The CPS sample is restricted to state-years where changes in all outcome variables from the prior year are observed, for a total of 495 observations in each regression. The text describes the sample composition further. Regressions are unweighted and cluster standard errors by state. Regressions include year fixed effects and control for contemporaneous changes in log state population, log state workforce, overall state labor force participation rate among worker age groups, overall state unemployment rate, log state income per capita, and overall mean log weekly wage for full-time male workers with bachelor's educations or higher in the state. Similar results are found without these controls for contemporaneous changes in state labor market conditions. 
Table 3: City-Year Regressions of H-1B Program Dependency and US Invention

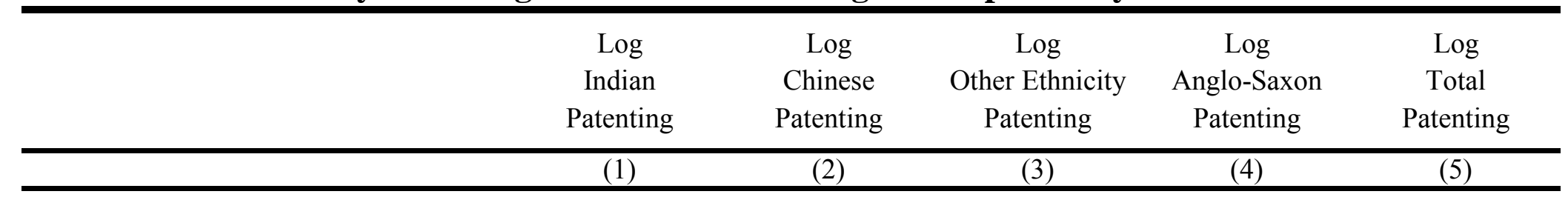

Log National H-1B Population $\mathrm{x}$

City Dependency [LCA]

Log National H-1B Population $\mathrm{x}$

$(0,1)$ Third Dependency Quintile

Log National H-1B Population $\mathrm{x}$

$(0,1)$ Second Dependency Quintile

Log National H-1B Population $\mathrm{x}$

$(0,1)$ Most Dependent Quintile [LCA]

Log National H-1B Population $\mathrm{x}$

City Dependency [LCA]

Log National H-1B Population $\mathrm{x}$

City Dependency [LCA]
(1)

A. LCA-Based Dependency
0.339

(0.048)

0.357

(0.096)

0.661

(0.089)

0.988

(0.077)
0.390

(0.061)
0.168

$(0.035)$

0.056

$(0.028)$

0.074

(0.028)

B. Quintiles Specification

$\begin{array}{cccc}0.343 & 0.219 & 0.053 & 0.071 \\ (0.098) & (0.108) & (0.106) & (0.106) \\ 0.833 & 0.382 & 0.116 & 0.125 \\ (0.106) & (0.088) & (0.089) & (0.084) \\ 1.208 & 0.507 & 0.180 & 0.227 \\ (0.092) & (0.088) & (0.090) & (0.089)\end{array}$

C. Including Tech. Trends, Local Labor Market Conditions, and Region-Year Effects
0.142
0.174
0.056
0.023
0.048
(0.045)
(0.061)
(0.034)
$(0.029)$
$(0.029)$

D. Panel C excluding Computers and Communications Patents
0.132
0.160
0.051
0.020
0.038
(0.045)
(0.059)
(0.035)
(0.029)
$(0.029)$

Notes: City-year regressions estimate the effect of changes in the national H-1B population over 1995-2007 for patenting by city. The annual H-1B population regressor is interacted with city-level dependencies as defined in Table 1. Panels A, C, and D present linear specifications where dependencies are normalized to have unit standard deviation before interacting. Panel B groups cities into quintiles based upon dependencies. The annual H-1B population regressor is interacted with binary indicator variables for the top three dependency quintiles to measure effects relative to the bottom two quintiles. Regressions include city and year fixed effects, are unweighted, have 3653 observations, and cluster standard errors by city. Panel $\mathrm{C}$ incorporates log expected patenting trends for each city-ethnicity, log city populations, log city mean income levels, and region-year fixed effects (nine Census regions). Panel D further excludes patents from the computer sector (USPTO category 2). 
Table 4: City-Year Regressions with Census-Based Dependency and Canadian Placebo

\begin{tabular}{|c|c|c|c|c|c|}
\hline & $\begin{array}{c}\text { Log } \\
\text { Indian } \\
\text { Patenting }\end{array}$ & $\begin{array}{c}\text { Log } \\
\text { Chinese } \\
\text { Patenting }\end{array}$ & $\begin{array}{c}\log \\
\text { Other Ethnicity } \\
\text { Patenting }\end{array}$ & $\begin{array}{c}\text { Log } \\
\text { Anglo-Saxon } \\
\text { Patenting }\end{array}$ & $\begin{array}{c}\text { Log } \\
\text { Total } \\
\text { Patenting }\end{array}$ \\
\hline & $(1)$ & $(2)$ & $(3)$ & $(4)$ & $(5)$ \\
\hline & \multicolumn{5}{|c|}{ A. Census-Based Dependency } \\
\hline \multirow[t]{2}{*}{$\begin{array}{l}\text { Log National H-1B Population x } \\
\text { City Dependency [Census] }\end{array}$} & $\begin{array}{c}0.240 \\
(0.031)\end{array}$ & $\begin{array}{c}0.291 \\
(0.047)\end{array}$ & $\begin{array}{c}0.091 \\
(0.029)\end{array}$ & $\begin{array}{c}0.014 \\
(0.023)\end{array}$ & $\begin{array}{c}0.032 \\
(0.023)\end{array}$ \\
\hline & \multicolumn{5}{|c|}{ B. Quintiles Specification } \\
\hline $\begin{array}{l}\text { Log National H-1B Population x } \\
(0,1) \text { Third Dependency Quintile }\end{array}$ & $\begin{array}{c}0.258 \\
(0.111)\end{array}$ & $\begin{array}{c}0.584 \\
(0.128)\end{array}$ & $\begin{array}{c}0.196 \\
(0.103)\end{array}$ & $\begin{array}{c}0.042 \\
(0.103)\end{array}$ & $\begin{array}{c}0.065 \\
(0.103)\end{array}$ \\
\hline $\begin{array}{l}\text { Log National H-1B Population x } \\
(0,1) \text { Second Dependency Quintile }\end{array}$ & $\begin{array}{c}0.444 \\
(0.092)\end{array}$ & $\begin{array}{c}0.529 \\
(0.119)\end{array}$ & $\begin{array}{c}0.232 \\
(0.098)\end{array}$ & $\begin{array}{c}0.088 \\
(0.103)\end{array}$ & $\begin{array}{c}0.092 \\
(0.098)\end{array}$ \\
\hline $\begin{array}{l}\text { Log National H-1B Population x } \\
(0,1) \text { Most Dependent Quintile [Census] }\end{array}$ & $\begin{array}{c}0.570 \\
(0.100)\end{array}$ & $\begin{array}{c}0.751 \\
(0.107)\end{array}$ & $\begin{array}{c}0.125 \\
(0.098)\end{array}$ & $\begin{array}{l}-0.012 \\
(0.083)\end{array}$ & $\begin{array}{c}0.028 \\
(0.085)\end{array}$ \\
\hline \multicolumn{6}{|c|}{ C. Including Tech. Trends, Local Labor Market Conditions, and Region-Year Effects } \\
\hline $\begin{array}{l}\text { Log National H-1B Population x } \\
\text { City Dependency [Census] }\end{array}$ & $\begin{array}{c}0.084 \\
(0.027)\end{array}$ & $\begin{array}{c}0.127 \\
(0.039)\end{array}$ & $\begin{array}{c}0.043 \\
(0.026)\end{array}$ & $\begin{array}{c}0.026 \\
(0.023)\end{array}$ & $\begin{array}{c}0.045 \\
(0.022)\end{array}$ \\
\hline & \multicolumn{5}{|c|}{ D. Panel $\mathrm{C}$ excluding Computers and Communications Patents } \\
\hline $\begin{array}{l}\text { Log National H-1B Population } \mathrm{x} \\
\text { City Dependency [Census] }\end{array}$ & $\begin{array}{c}0.089 \\
(0.026)\end{array}$ & $\begin{array}{c}0.107 \\
(0.044)\end{array}$ & $\begin{array}{c}0.042 \\
(0.030)\end{array}$ & $\begin{array}{c}0.020 \\
(0.023)\end{array}$ & $\begin{array}{c}0.038 \\
(0.024)\end{array}$ \\
\hline & \multicolumn{5}{|c|}{ E. Placebo Experiment with Canadian Sample of Cities } \\
\hline $\begin{array}{l}\text { Log National H-1B Population x } \\
\text { City Dependency [Census] }\end{array}$ & $\begin{array}{l}-0.039 \\
(0.065)\end{array}$ & $\begin{array}{c}0.097 \\
(0.086)\end{array}$ & $\begin{array}{c}0.045 \\
(0.048)\end{array}$ & $\begin{array}{c}0.015 \\
(0.067)\end{array}$ & $\begin{array}{c}0.029 \\
(0.055)\end{array}$ \\
\hline
\end{tabular}

Notes: See Table 3. Panels A-D consider the Census-based dependency of the city instead of using the LCA-based dependency. Panel E further considers a placebo experiment with Canadian cities for which pseudo-dependencies can be calculated from the 1991 Canadian Census. 
Table 5: Descriptive Statistics for Firm Panel

\begin{tabular}{|c|c|c|c|c|c|}
\hline & Median & Mean & Stand. Dev. & Minimum & Maximum \\
\hline \multicolumn{6}{|l|}{ Firm-Level Patenting } \\
\hline Annual Patent Count & 167 & 345 & 499 & 42 & 3,501 \\
\hline Indian Inventors & $6 \%$ & $8 \%$ & $5 \%$ & $1 \%$ & $32 \%$ \\
\hline Chinese Inventors & $9 \%$ & $10 \%$ & $6 \%$ & $2 \%$ & $28 \%$ \\
\hline Other Ethnic Inventors & $22 \%$ & $22 \%$ & $4 \%$ & $9 \%$ & $43 \%$ \\
\hline Anglo-Saxon Inventors & $62 \%$ & $60 \%$ & $11 \%$ & $34 \%$ & $81 \%$ \\
\hline Chemicals & $6 \%$ & $14 \%$ & $17 \%$ & $0 \%$ & $76 \%$ \\
\hline Computers \& Communications & $16 \%$ & $28 \%$ & $29 \%$ & $0 \%$ & $99 \%$ \\
\hline Drugs \& Medical & $0 \%$ & $16 \%$ & $29 \%$ & $0 \%$ & $89 \%$ \\
\hline Electrical \& Electronic & $12 \%$ & $19 \%$ & $20 \%$ & $0 \%$ & $96 \%$ \\
\hline Mechanical & $5 \%$ & $12 \%$ & $14 \%$ & $0 \%$ & $55 \%$ \\
\hline Miscellaneous & $4 \%$ & $10 \%$ & $15 \%$ & $0 \%$ & $72 \%$ \\
\hline New England & $2 \%$ & $6 \%$ & $14 \%$ & $0 \%$ & $93 \%$ \\
\hline Middle Atlantic & $1 \%$ & $15 \%$ & $27 \%$ & $0 \%$ & $94 \%$ \\
\hline East North Central & $1 \%$ & $19 \%$ & $31 \%$ & $0 \%$ & $97 \%$ \\
\hline West North Central & $0 \%$ & $4 \%$ & $13 \%$ & $0 \%$ & $80 \%$ \\
\hline South Atlantic & $2 \%$ & $7 \%$ & $15 \%$ & $0 \%$ & $84 \%$ \\
\hline East South Central & $0 \%$ & $2 \%$ & $11 \%$ & $0 \%$ & $95 \%$ \\
\hline West South Central & $1 \%$ & $10 \%$ & $23 \%$ & $0 \%$ & $98 \%$ \\
\hline Mountain & $1 \%$ & $4 \%$ & $10 \%$ & $0 \%$ & $79 \%$ \\
\hline Pacific & $10 \%$ & $32 \%$ & $38 \%$ & $0 \%$ & $98 \%$ \\
\hline \multicolumn{6}{|l|}{ Firm-Level LCA Applications } \\
\hline Annual LCA Count & 53 & 171 & 333 & 0 & 2,254 \\
\hline \multicolumn{6}{|l|}{ Firm-Level Compustat Activity } \\
\hline Annual Sales (\$m) & 9,538 & 22,455 & 37,508 & 18 & 193,289 \\
\hline Annual Employees (k) & 37 & 65 & 91 & 0 & 567 \\
\hline Annual R\&D (\$m) & 519 & 1,224 & 1,637 & 17 & 8,413 \\
\hline
\end{tabular}

Notes: Descriptive statistics for 77 firms including in firm panel for 1995-2007. 
Table 6: Firm-Year Regressions of H-1B Program Dependency and US Invention

\begin{tabular}{|c|c|c|c|c|c|}
\hline & $\begin{array}{l}\text { Log } \\
\text { Indian } \\
\text { Patenting }\end{array}$ & $\begin{array}{l}\text { Log } \\
\text { Chinese } \\
\text { Patenting }\end{array}$ & $\begin{array}{l}\text { Log } \\
\text { Other Ethnicity } \\
\text { Patenting }\end{array}$ & $\begin{array}{l}\text { Log } \\
\text { Anglo-Saxon } \\
\text { Patenting }\end{array}$ & $\begin{array}{c}\text { Log } \\
\text { Total } \\
\text { Patenting }\end{array}$ \\
\hline & $(1)$ & $(2)$ & (3) & (4) & $(5)$ \\
\hline & \multicolumn{5}{|c|}{ A. LCA-Based Dependency } \\
\hline \multirow[t]{2}{*}{$\begin{array}{l}\text { Log National H-1B Population x } \\
\text { Firm Dependency [LCA] }\end{array}$} & $\begin{array}{c}0.452 \\
(0.120)\end{array}$ & $\begin{array}{c}0.315 \\
(0.114)\end{array}$ & $\begin{array}{c}0.357 \\
(0.080)\end{array}$ & $\begin{array}{c}0.256 \\
(0.077)\end{array}$ & $\begin{array}{c}0.331 \\
(0.077)\end{array}$ \\
\hline & \multicolumn{5}{|c|}{ B. Including Tech. Trends and Region-Sector-Year Effects } \\
\hline \multirow[t]{2}{*}{ Firm Dependency [LCA] } & $\begin{array}{c}0.497 \\
(0.143)\end{array}$ & $\begin{array}{c}0.379 \\
(0.153)\end{array}$ & $\begin{array}{c}0.370 \\
(0.097)\end{array}$ & $\begin{array}{c}0.246 \\
(0.106)\end{array}$ & $\begin{array}{c}0.335 \\
(0.099)\end{array}$ \\
\hline & \multicolumn{5}{|c|}{ C. Panel B with Interaction for Computer Sector } \\
\hline $\begin{array}{l}\text { Log National H-1B Population } \mathrm{x} \\
\text { Firm Dependency [LCA] }\end{array}$ & $\begin{array}{c}0.336 \\
(0.170)\end{array}$ & $\begin{array}{c}0.144 \\
(0.202)\end{array}$ & $\begin{array}{c}0.278 \\
(0.106)\end{array}$ & $\begin{array}{c}0.149 \\
(0.122)\end{array}$ & $\begin{array}{c}0.216 \\
(0.120)\end{array}$ \\
\hline $\begin{array}{l}\text { Log National H-1B Population } \mathrm{x} \\
\text { Firm Dependency [LCA] x } \\
(0,1) \text { Computer Sector }\end{array}$ & $\begin{array}{c}0.449 \\
(0.262)\end{array}$ & $\begin{array}{c}0.656 \\
(0.300)\end{array}$ & $\begin{array}{c}0.255 \\
(0.174)\end{array}$ & $\begin{array}{c}0.271 \\
(0.192)\end{array}$ & $\begin{array}{c}0.332 \\
(0.181)\end{array}$ \\
\hline
\end{tabular}

\footnotetext{
Notes: Firm-year regressions consider 1995-2007. Regressions include firm and year fixed effects, have 1001 observations, are unweighted, and cluster standard errors by firm. Panel B incorporates expected technology trends for each firm and region-sector-year fixed effects. Section 4.4 describes the construction of the expected technology trends. We define regions through the four Census regions and sectors through patent categories. On both dimensions, firms are classified by where they patent the most during the sample period. Panel $\mathrm{C}$ further distinguishes effects within and outside of the computer sector. We interact the core regressor with an indicator variable for the computer and communications patent category. We demean both regressors before interaction to restore main effects, and the main effect for the computer-oriented sector is absorbed by the region-sector-year fixed effects.
} 